\title{
Profit Distribution and Stability Analysis of Joint Distribution Alliance Based on Tripartite Evolutionary Game Theory Under the Background of Green and Low-Carbon
}

\section{Renbin Han ( $\sim$ 1324696297@qq.com )}

Beijing University of Posts and Telecommunications

Mengke Yang

Beijing University of Posts and Telecommunications

\section{Research Article}

Keywords: green and low-carbon, evolutionary game, joint distribution, profit distribution, stability of alliance, numerical simulation

Posted Date: September 24th, 2021

DOl: https://doi.org/10.21203/rs.3.rs-660223/v1

License: (c) (1) This work is licensed under a Creative Commons Attribution 4.0 International License. Read Full License

Version of Record: A version of this preprint was published at Environmental Science and Pollution Research on April 7th, 2022. See the published version at https://doi.org/10.1007/s11356-022-19712-y. 


\title{
Profit Distribution and Stability Analysis of Joint Distribution Alli- ance Based on Tripartite Evolutionary Game Theory Under the Background of Green and Low-Carbon
}

\author{
Renbin Han ${ }^{1, *}$ and Mengke Yang ${ }^{2}$
}

${ }^{1}$ School of Modern Post (School of Automation), Beijing University of Posts and Telecommunications, Beijing 100876, China; 1324696297@qq.com

${ }^{2}$ School of Modern Post (School of Automation), Beijing University of Posts and Telecommunications, Beijing 100876, China; yangmengke@139.com

* Correspondence: $1324696297 @ q q . c o m$

\begin{abstract}
Joint distribution is an advanced logistics organization model for improving the quality and efficiency of express logistics industry and achieve high-quality development of logistics, but the distribution of common profit has always been a key obstacle to the effective development of joint distribution. Based on the background of green and low-carbon, this paper explores a fairer and more reasonable profit distribution scheme. The profit game between the government and the two types of member enterprises is analyzed. By focusing on how the government plays a role in inducing the joint distribution alliance to bring the green and low-carbon requirements into the profit distribution, the strategy evolution process of the three parties, the factors affecting the profit distribution and the stability of alliance are discussed through the establishment of "governmentmember enterprise A-member enterprise B" tripartite evolutionary game model. Finally, the evolutionary game model is numerically simulated based on system dynamics. It is found that: (1) It is necessary for the government to guide and motivate the alliance to create internal incentives and constraints. The effect of government subsidies and rewards to member enterprises is greater than the penalties for member enterprises. (2) The member enterprises are likely to conspire together to defraud government subsidies and rewards, carry out "free riding" and other speculative activities, which makes it necessary for the government and the alliance to establish supervision mechanism, information disclosure mechanism, and property rights protection system. (3) The willingness of member enterprise to positively cooperate will increase with the increase of the additional benefit coefficient, the proportion of profit distribution and the importance of environmental benefit factor; and will decrease with the increase of the cost of promoting green distribution operations.
\end{abstract}

Keywords: green and low-carbon; evolutionary game; joint distribution; profit distribution; stability of alliance; numerical simulation 
et al. 2018; Li et al. 2019) realized the importance of environmental sustainability, and introduced ecological and environmental factors to improve profit distribution methods and models. There are also scholars who combined a variety of game models, such as incomplete information dynamic game model, stackelberg model, to analyze the game behaviors and profit distribution relationships between member enterprises in an alliance (Du ZP and Gong XL 2018), among which the evolutionary game model is widely used.

Evolutionary game theory is a theory that combines game theory analysis with dynamic evolution process analysis. It holds that humans improve their strategies by continuous learning and imitation, rather than taking the optimal strategies from the beginning. Compared with traditional game theory, evolutionary game theory assumes that humans are bounded rational. Owing to players with bounded rationality have multiple levels of rationality, their ways and speeds of learning and strategy adjustment are quite different, and it is almost impossible to obtain the optimal results in the fast changing economic activities, so the perspective of evolutionary game are necessarily used to simulate the evolution of and the interactive relationship between the players' strategies, which reflect the reality better.Scholars at home and abroad have used evolutionary game theory to study the strategic interaction between member enterprises in a logistics alliance, the stability of alliance, and the factors affecting the stability of alliance. Huang et al. (2010) focused on the investment efficiency of specific assets within the alliance and the trust mechanism associated with it. By establishing a two-party evolutionary game model between the demand side and the supply side of logistics services, they made it clear that the equivalence and soundness of the trust mechanism have a positive impact on the stability of logistics alliance and the specific asset investment efficiency. Xu et al. (2011) discussed the formation mechanism of logistics alliance, considered risk aversion conditions when establishing the alliance's collaboration game model, and analyzed the factors that affect the investment of logistics enterprises. Li et al. (2012) put forward a two-party evolutionary game model to describe the cooperation and coordination process within the alliance formed by logistics enterprises of the same nature in an asymmetric state, pointed out that factors such as cooperation cost, retained profit, alliance profit, and profit distribution rate have an impact on the stability of logistics alliance. Wu et al. (2014) believed that the stability of cooperation between regional logistics alliance member enterprises is related to time discount factors, enterprise profit, and alliance constraint mechanisms, and it is necessary for the government to take measures to reward and punish the member enterprises so that the benefits of betraying the alliance are always less than the benefits of cooperation. Sun et al. (2014) focused on the joint distribution of urban cold chain logistics, established a two-party evolutionary game model and found that the member enterprise's willingness to cooperate is affected by initial input costs, profit distribution, and degree of mutual dependence. Wang et al. (2015) conducted incomplete information dynamic game analysis on the leading logistics enterprises, other logistics enterprises and production enterprises in a logistics alliance, and discussed the equilibrium conditions for the formation of logistics alliance. Liu et al. (2015) explored the motivation and stability factors of the formation of logistics alliance by establishing a two-party evolutionary game model between third-party logistics enterprises and functional logistics enterprises, concluded that the higher the cooperation cost of member enterprises and the lower the fees paid by third-party logistics to functional logistics, the lower the probability that the alliance can be formed and maintained stable. Du et al. (2018) initially identified the operational risks of cross-border logistics alliance, and then established an evolutionary game model under the alliance's internal punishment mechanism, believed that it is necessary for the alliance to establish a scientific punishment mechanism to prevent speculative activities by member enterprises and avoid the operation risks of alliance. Zou et al. (2019) established a co-evolution game model for self-operated logistics packaging enterprises and logistics outsourcing third-party packaging enterprises, and pointed out that product market share, synergy cost, synergy effect, synergy cost sharing, revenue sharing ratio have an impact on the synergy between the two. Du et al. (2019) put forward an evolutionary game model between domestic cross-border e-commerce enterprises and foreign logistics enterprises, and found that the willingness of both parties to cooperate depends on the initial state of cooperation, input costs, excess returns and cloud technology platform. Based on the evolutionary game model of collaborative innovation between manufacturing enterprises and logistics enterprises, Yu et al. (2019) found that under the influence of market mechanism, only when the enterprise's collaborative innovation benefits are higher than the sum of the "free-riding" benefits and investment, can the alliance reach a stable state of collaborative innovation. ("Free-riding" means the act of obtaining benefits from others without paying any cost). The greater the intensity of government subsidies and penalties, the more conducive to the formation of the alliance. Besides, the profit distribution ratio, input costs, and knowledge transfer efficiency have an impact on the stability of alliance. Chen et al. (2019) divided alliance member enterprises into three categories according to input elements and market power, established a tripartite evolutionary game model and analyzed the factors that affect the strategic choices of the three parties, concluded that the intensity of punishment, transaction costs among member enterprises, and speculative gains have significant influence on the strategic choice of member enterprises and the stability of logistics alliance. The incentive and preferential policies among the member enterprises can promote more active cooperation of the member enterprises than the unilateral alliance punishment. After establishing a co-evolution game model of cross-border e-commerce and cross-border logistics, Mou et al. (2020) found that the co-evolution of the two features obvious path dependence, and the path and state of the evolutionary game between the two will change with the changes of the initial state and the return matrix. Fu et al. (2020) analyzed the strategy evolution path of cross-border logistics alliance member enterprises by establishing a two-party evolutionary game model between domestic logistics enterprises and foreign logistics enterprises, and believed that the stability of alliance is affected by the profit distribution mechanism, the scale of resource input and operational efficiency. Du et al. (2020) proposed a tripartite evolutionary game model of "cross-border e-commerce platform-logistics service provider-merchant" for the cross-border e-commerce logistics alliance based on 4PL. In addition, there are analyses highlighting the impact of information sharing and information collaboration on logistics alliance. For example, Zhang et al. (2017) believed that in the initial stage of the formation of logistics alliance, the proportion of information resource input affects the construction of logistics alliance. During the operation of the logistics alliance, the sharing degree of information resources between member enterprises, the benefits brought about by the reduction of shared information resources, overflow benefits, and the degree of loss affect the member enterprises' decision-making and the stability of alliance. Hu et al. (2018) believed that increasing the degree of information sharing will increase the willingness of enterprises to cooperate positively, and the total profit of the alliance and the proportion of profit distribution also increase accordingly, which is beneficial to the stability of alliance. Zhang et al. (2020) believed that supply chain logistics information collaboration (SCLIC) is the basis 
and premise of supply chain logistics collaboration, analyzed the evolution game process of suppliers, manufacturers, and their combination by establishing a two-level supply chain evolution game model composed of suppliers and manufacturers.

What's more, other documents (Li et al. 2017; Ji et al. 2018; Liang et al. 2017; Gu et al. 2017; Zhang et al. 2019; He et al. 2021; Xing et al. 2020; Xu et al. 2021; Zhu et al. 2021; Wang et al. 2021) took into account the important role of government participation, regarded the government as a participant, conducted the evolution game analysis of cold chain logistics, reverse logistics, crossborder e-commerce \& logistics, combined transport by road transport enterprises and railway transport enterprises, strategic interaction between manufacturing enterprises and logistics enterprises, etc. by introducing government rewards, government punishment and regulatory mechanism. Especially, Zhang et al. (2019) discussed the behavioral mechanism of joint distribution alliance under government supervision based on the background of sustainable development. They believed that in the early stage of implementing joint distribution, the government needs to subsidize and reward member enterprises, or increase the penalties for noncooperation of member enterprises to promote the formation of a benign logistics environment and market mechanism. As long as the government's goals are achieved, the benefits of cooperation within the alliance are improved and costs are reduced, the government can then withdraw its supervision. Zhang et al. (2020) also introduced government reward and punishment mechanism, used evolutionary game theory to explore the behavioral mechanism of joint distribution alliance member enterprises and the factors that affect the implementation of joint distribution.

Besides, owing to strong shocks to society and the economy from environmental problems, green and low-carbon development patterns have gradually attracted more attention from all over the world (Wu B et al. 2017). Many scholars studied the strategic game relationships between the government and various market participants under the background of green and low carbon (Zhao R et al. 2016; Fan RG et al. 2017; Wu B et al. 2017; Zhang LP et al. 2019; Sun T and Feng Q 2021). At this time, the research field is no longer limited to logistics, but also covers electric vehicles (Hirte G and Tscharaktschiew S 2013; Liu C et al. 2017; Zhou X et al. 2019; Du ZL et al. 2019), green supply chain (Sheu JB and Chen YM 2012; Hafezalkotob A et al. 2016; Madani SR and RastiBarzoki M 2017; Zu YF et al. 2018; Mahmoudi R and Rasti-Barzoki M 2018; Yuan BY et al. 2018; Hafezalkotob A 2018; Shi YY et al. 2020; Long QQ et al. 2021), e-waste (Peng BH et al. 2019) and so on.

In summary, although scholars have recognized the impact of environmental sustainability on the behavioral decisions of express logistics enterprises, consider the environmental benefits when discussing profit distribution of joint distribution alliance, they pay so much attention to discuss the profit distribution methods that lack the research on the profit distribution mechanism, especially on how to incorporate the green and low-carbon requirements into the alliance's profit distribution scheme. It should be noted that there is no conscious motivation for joint distribution alliance to incorporate the green and low-carbon requirements into the profit distribution scheme so as to formulate a fairer and more reasonable profit distribution scheme. Whether it is necessary for the government to participate and what kind of policy means and tools should be used to promote the formation of this mechanism is worth thinking about. Besides, some scholars believe that profit distribution is closely related to the stability of alliance, the stability of logistics alliance, including joint distribution alliance, is not static. There are many studies on the stability of logistics alliance from the perspective of evolutionary game theory, but there is a lack of research on the impact of the alliance's internal profit distribution strategy on the stability of alliance, especially when the profit distribution takes into account the green and low-carbon requirements, will the alliance continue to remain stable? Therefore, based on previous research and from the perspective of evolutionary game, this paper initially divides the member enterprises into two types (A and B) according to the volume and green level of distribution, and regards the government as one of the participants, then puts forward the "government-member enterprise Amember enterprise B" tripartite evolutionary game model to explore the government's important role in guiding and motivating alliance to incorporate green and low-carbon requirements into profit distribution scheme, the strategy evolution paths, the interaction between the tripartite participants involved in this process, and the factors that affect the stability of alliance. Finally, according to the system dynamics, the tripartite evolutionary game is numerically simulated to study the influence of the different decisionmaking behaviors of the three parties on their stable operation status, reveal the formation process of the alliance's profit distribution mechanism considering the green and low-carbon requirements under government participation. On this basis, this paper will enrich the related theoretical results, provide decision-making reference for the government to promote the reasonable distribution of common profit and green development of the logistics alliance.

\section{Profit Game Analysis of the Three Parties}

Promoting the green development of the express logistics industry is the general trend. Although joint distribution has the advantages of reducing the number of vehicles used for distribution, increasing the loading rate of vehicles, thereby reducing carbon emissions, pollution emissions, and increasing environmental benefits (Bi KX et al. 2020), it does not mean that joint distribution can completely eliminate the negative externalities brought by member enterprises to the cities and the environment, nor does it mean that member enterprises have endogenous motivation to promote green distribution operations. Promoting green distribution operations usually costs member enterprises a lot, if so, member enterprises are likely to recoup the cost of green distribution operations by sharply raising the price of delivery services. However, in reality, that's a price level the market can't afford. Since joint distribution is an advanced logistics organization method vigorously advocated by the state, it is necessary for express logistics enterprises to reflect green and low-carbon requirements in the process of forming a joint distribution alliance and implementing joint distribution.

Based on the hypothesis that humans are rational, member enterprises pursue the maximization of their own profit. If the marginal transaction cost of joint distribution from the market is lower than the marginal organization cost of distribution organized by member enterprise itself, member enterprises will form and participate in the alliance; otherwise, they will withdraw and disband the alliance (Yang MK and Han RB 2021).

According to the reality, member enterprises can be divided into two types: one is large enterprises with a larger volume of delivery and a higher level of green distribution operations (denoted as member enterprise A), and the other is small and mediumsized enterprises with a smaller volume of delivery and a lower level of green distribution operations (denoted as member enterprise B). The reason why member enterprise A hopes to form an alliance with member enterprise B is that it can take advantage of large- 
scale distribution operations by cooperating with member enterprise B, reduce fixed cost per unit of delivery, and reach economies of scale. Meanwhile, member enterprise B hopes to cooperate with member enterprise A because it can get help from member enterprise A to promote green distribution operations, reduce its distribution costs, improve its distribution efficiency, as well as enhance its brand awareness in the process of cooperation. Considering the high costs, high risks, and long return period of greening distribution operations, neither of them has the motivation to implement the green and low-carbon requirements spontaneously. As for a single express logistics enterprise, it promotes green distribution operations under the dual effects of internal power and external pressure. However, if there is a conflict of profit with its stakeholders, coupled with a lack of endogenous power and external pressure, its process of green development will become difficult. For this reason, it is necessary for the government to motivate and supervise the enterprise (Li SH and WANG XJ 2014). As for the alliance, the co-opetition relationship between member enterprises, the difference in strategic choices, and the difference in the ability to promote green distribution operations make the implementation of green and low-carbon requirements within the alliance quite different from the situation of a single enterprise. If the market mechanism cannot help member enterprises spontaneously implement green and low-carbon requirements, then governments committed to maximizing social and economic benefits, including environmental benefits, should participate and induce member enterprises to consciously incorporate green and low-carbon requirements into joint distribution. In other words, the government can guide the alliance to take environmental benefits as one of the important factors affecting profit distribution and put it into the alliance's profit distribution scheme through necessary policy means and tools, so as to overcome the defect of profit distribution merely based on marginal business contribution of member enterprises in the past. The member enterprise who implements the green and low-carbon requirements better, has a higher level of green distribution operations, and creates greater environmental benefits can be allocated more profit. At this time, member enterprise A will be more motivated to promote green distribution operations, and though member enterprise B is not as good as member enterprise A in terms of distribution volume, it can seize this opportunity to improve its green level of distribution operations in order to obtain more profit. It is worth mentioning that government subsidies, rewards and penalties to the alliance are important parts of the government's strategy. Government subsidies and rewards can narrrow the gap between the common profit of the alliance in the process of promoting green distribution operations and the common profit of alliance without promoting green distribution operations, reduce the risks and costs of member enterprises in implementing green and low-carbon requirements, and thus improve the stability of alliance. What can be not ignored is that all member enterprises may have opportunistic behaviors, which is not only manifested as defrauding government subsidies and rewards, but also as "free riding" behavior, for which the government must punish.

It can be seen from the above that each player's strategy choice not only depends on its own profit expectation, but also depends on the strategy choice of other players. All players' strategies are not always the same, but will be adjusted as time goes on.

\section{The Construction of Tripartite Evolutionary Game Model}

\subsection{Model Hypothesis}

Hypothesis 1. The government is participant 1, member enterprise A is participant 2, and member enterprise B is participant 3. All of them have bounded rationality, not only pursuing the maximization of their own profits, but also often failing to find the optimal strategies at the very beginning. They constantly adjust their own strategy choices based on their experience, and finally reach a stable equilibrium.

Hypothesis 2. The game between the three parties belongs to the asymmetric game, and the game strategies adopted by the three parties influence each other. The profit of any party depends not only on its own strategy choice, but also on the strategy choices of the other two parties.

Hypothesis 3. The government's strategy space is (incentive, non-incentive), in which the "incentive" strategy refers to subsidies, rewards and punishments coming from the government in the process of implementing green and low-carbon requirements; the "non-incentive" strategy refers to not subsidizing, rewarding or punishing member enterprises, hoping that member enterprises will consciously implement green and low-carbon requirements. The strategy space of member enterprise A is (positive cooperation, negative cooperation), in which the "positive cooperation" strategy refers to positively responding to the government's call to implement green and low-carbon requirements; the "negative cooperation" strategy refers to not responding to the government's call and not implementing green low-carbon Carbon requirements. The strategy space of member enterprise B is (positive cooperation, negative cooperation), in which the "positive cooperation" strategy refers to positively responding to the government's call to implement green and low-carbon requirements; the "negative cooperation" strategy refers to not responding to the government's call and not implementing green low-carbon requirements.

\subsection{Model Parameters}

Although the government, member enterprise A, and member enterprise B are stakeholders, their objectives and strategies are different. The relevant parameters are assumed and shown in Table 1.

Table 1. The parameters and their meanings.

\begin{tabular}{|c|c|c|}
\hline Participants & Paremeters & Meanings \\
\hline \multirow{3}{*}{ Government } & $R_{g_{1}}$ & $\begin{array}{l}\text { The environmental benefits created by the alliance's implementation of green and low-carbon re- } \\
\text { quirements under government incentives }\end{array}$ \\
\hline & $R_{g_{2}}$ & $\begin{array}{l}\text { The environmental benefits created by the alliance's implementation of green and low-carbon re- } \\
\text { quirements without the government incentives }\end{array}$ \\
\hline & $C_{g}$ & $\begin{array}{l}\text { The governance costs that the government has to bear due to the alliance's failure to implement } \\
\text { green and low-carbon requirements without government incentives }\end{array}$ \\
\hline
\end{tabular}




\begin{tabular}{|c|c|c|}
\hline & $T_{g}$ & $\begin{array}{l}\text { The administrative penalties that the government has to bear due to member enterprises defraud- } \\
\text { ing government subsidies or the government's failure to incentivize the alliance }\end{array}$ \\
\hline & $M_{g}$ & The cost of government incentives \\
\hline & $\beta_{1} L_{1}$ & $\begin{array}{l}\text { Subsidies and rewards given to member enterprise } \mathrm{A} \text { under government incentives. } \beta_{1} \text { means the } \\
\text { intensity of government subsidies and rewards for member enterprise } \mathrm{A}, 0<\beta_{1}<1\end{array}$ \\
\hline & $\beta_{2} L_{2}$ & $\begin{array}{l}\text { Subsidies and rewards given to member enterprise B under government incentives. } \beta_{2} \text { means the } \\
\text { intensity of government subsidies and rewards for member enterprise } \mathrm{B}, 0<\beta_{2}<1\end{array}$ \\
\hline & $\gamma_{1} P_{1}$ & $\begin{array}{l}\text { Penalties for both member enterprises when they cooperate negatively under government incen- } \\
\text { tives. } \gamma_{1} \text { means the intensity of government's punishment on both member enterprises, } 0<\gamma_{1}<\end{array}$ \\
\hline & $\gamma_{2} P_{2}$ & $\begin{array}{l}\text { Penalties for member enterprise B when member enterprise A cooperates positively and member } \\
\text { enterprise B cooperates negatively under government incentives. } \gamma_{2} \text { means the intensity of govern- } \\
\text { ment's punishment on member enterprise B, } 0<\gamma_{2}<1\end{array}$ \\
\hline & $\gamma_{3} P_{3}$ & $\begin{array}{c}\text { Penalties for member enterprise A when member enterprise B cooperates positively and member } \\
\text { enterprise A cooperates negatively under government incentives. } \gamma_{3} \text { means the intensity of gov- } \\
\text { ernment's punishment on member enterprise A, } 0<\gamma_{3}<1\end{array}$ \\
\hline & $\alpha I$ & $\begin{array}{c}\text { The government's investment in the construction of joint distribution infrastructure. } \alpha \text { means the } \\
\text { investment intensity, } 0<\alpha<1\end{array}$ \\
\hline & $R_{A_{1}}$ & The profit obtained by member enterprise A when it positively cooperates \\
\hline & $\overline{C_{A_{1}}}$ & The distribution costs that member enterprise A positively cooperates, $C_{A_{1}}=G_{A}+C_{A_{2}}$ \\
\hline & $G_{A}$ & The cost that member enterprise A promotes green distribution operations \\
\hline & $\theta R$ & $\begin{array}{l}\text { The profit of member enterprise A when it negatively cooperates. } \theta \text { means member enterprise } \\
\text { A's proportion in the profit distribution }\end{array}$ \\
\hline & $C_{A_{2}}$ & The distribution costs that member enterprise A negatively cooperates \\
\hline & $\lambda \theta R$ & $\begin{array}{l}\text { Member enterprise A's additional benefits resulting from positive cooperation between both mem- } \\
\text { ber enterprises (such as economies of scale, etc.). } \lambda \text { means the additional benefit coefficient of } \\
\text { member enterprise } \mathrm{A}, 0<\lambda<1\end{array}$ \\
\hline & $R_{A_{3}}$ & Speculative gains when member enterprise A negatively cooperates (such as defraudation) \\
\hline & $C_{A_{3}}$ & The risk cost that member enterprise A negatively cooperates (such as defraudation) \\
\hline & $L_{A}$ & Member enterprise A's additional losses caused by member enterprise B's negative cooperation \\
\hline & $R_{B_{1}}$ & The profit obtained by member enterprise B when it positively cooperates \\
\hline & $C_{B_{1}}$ & The distribution cost that member enterprise B positively cooperates, $C_{B_{1}}=G_{B}+C_{B_{2}}$ \\
\hline & $G_{B}$ & The cost that member enterprise B promotes green distribution operations \\
\hline & $(1-\theta) R$ & The profit of member enterprise B when it negatively cooperates \\
\hline & $C_{B_{2}}$ & The distribution costs that member enterprise B negatively cooperates \\
\hline enterprise B & $\varphi(1-\theta) R$ & $\begin{array}{c}\text { Member enterprise B's additional benefits resulting from positive cooperation between both mem- } \\
\text { ber enterprises (such as brand awareness, etc.). } \varphi \text { means the additional benefit coefficient of } \\
\text { member enterprise B, } 0<\varphi<1\end{array}$ \\
\hline & $R_{B_{3}}$ & $\begin{array}{c}\begin{array}{l}\text { Speculative gains when member enterprise B negatively cooperates (such as "free-riding" behav- } \\
\text { ior) }\end{array} \\
\end{array}$ \\
\hline & $C_{B_{3}}$ & The risk cost when member enterprise B negatively cooperates (such as "free-riding" behavior) \\
\hline & $R$ & $\begin{array}{c}\text { The total profit of the joint distribution alliance without considering the green and low-carbon re- } \\
\text { quirements (total profit that both types of enterprises cooperate negatively) }\end{array}$ \\
\hline & $\tau R$ & $\begin{array}{l}\text { The Profit caused by environmental benefits factor when considering green and low-carbon re- } \\
\text { quirements. } \tau \text { means the proportion of the profit caused by environmental benefits factor, } 0< \\
\qquad<<1\end{array}$ \\
\hline $\begin{array}{l}\text { enterprise A and } \\
\text { Member } \\
\text { enterprise B }\end{array}$ & $\xi \tau R$ & $\begin{array}{l}\text { Incremental profit obtained by member enterprises A after considering the green and low-carbon } \\
\text { requirements to redistribute the total profit. } \xi \text { means the proportion of the profits allocated by } \\
\text { member enterprise A to the profit caused by environmental benefit factor, } 0<\xi<1\end{array}$ \\
\hline & $S$ & $\begin{array}{l}\text { Transaction costs of the cooperation between both member enterprises. If both enterprises posi- } \\
\text { tively cooperate, the transaction costs will decrease; if one of them negatively cooperates, the } \\
\text { transaction costs will increase }\end{array}$ \\
\hline
\end{tabular}

\subsection{Model Construction}

\subsubsection{Profit Matrix between the Three Parties}

Based on the above model hypotheses and parameters, the profit matrix between government, member enterprise A, and member enterprise B can be formed, as shown in Table 2 below. The probability of government adopting incentive strategy is $\mathrm{x}$, and the 
probability of government adopting non-incentive strategy is (1-x). The probability of member enterprise A adopting "positive cooperation" strategy is $\mathrm{y}$, and the probability of member enterprise A adopting "negative cooperation" strategy is (1 -y). The probability of member enterprise B adopting "positive cooperation" strategy is $\mathrm{z}$, and the probability of member enterprise B adopting "negative cooperation" strategy is $(1-\mathrm{z}) . \mathrm{x}, \mathrm{y}, \mathrm{z} \in[0,1]$.

Table 2. a). The profit matrix between the government, member enterprise A, and member enterprise B.

\begin{tabular}{|c|c|c|c|c|}
\hline \multirow{2}{*}{ Enterprise B } & \multicolumn{2}{|c|}{ Government: Incentives $(\boldsymbol{x})$} & Government: Non-incentives $(\mathbf{1}-\boldsymbol{x})$ \\
\cline { 2 - 5 } & $\begin{array}{c}\text { Enterprise A: Positive Co- } \\
\text { operation }(\boldsymbol{y})\end{array}$ & $\begin{array}{c}\text { Enterprise A: Negative } \\
\text { Cooperation }(\mathbf{1}-\boldsymbol{y})\end{array}$ & $\begin{array}{c}\text { Enterprise A: Posi- } \\
\text { tive Cooperation }(\boldsymbol{y})\end{array}$ & $\begin{array}{c}\text { Enterprise A: Neg- } \\
\text { ative Coopera- } \\
\text { tion }(\mathbf{1}-\boldsymbol{y})\end{array}$ \\
\hline $\begin{array}{c}\text { Positive Cooperation }(\boldsymbol{z}) \\
\begin{array}{c}\text { Negative Cooperation } \\
(\mathbf{1}-\boldsymbol{z})\end{array}\end{array}$ & $\left(a_{1}, b_{1}, c_{1}\right)$ & $\left(a_{2}, b_{2}, c_{2}\right)$ & $\left(a_{3}, b_{3}, c_{3}\right)$ & $\left(a_{4}, b_{4}, c_{4}\right)$ \\
$\left(a_{5}, b_{5}, c_{5}\right)$ & $\left(a_{6}, b_{6}, c_{6}\right)$ & $\left(a_{7}, b_{7}, c_{7}\right)$ & $\left(a_{8}, b_{8}, c_{8}\right)$ \\
\hline
\end{tabular}

Table 2. b). The profit matrix between the government, member enterprise A, and member enterprise B.

\begin{tabular}{|c|c|c|c|}
\hline & Government & Member Enterprise A & Member Enterprise B \\
\hline$\left(a_{1}, b_{1}, c_{1}\right)$ & $R_{g_{1}-M_{g}-\beta_{1} L_{1}-\beta_{2} L_{2}-\alpha I}$ & $\theta(R-\tau R)+\xi \tau R-C_{A}-G_{A}+\lambda \theta R+\beta_{1} L_{1}+S$ & $(1-\theta)(R-\tau R)+(1-\xi) \tau R-C_{B}-G_{B}+\varphi(1-\theta) R+$ \\
\hline$\left(a_{2}, b_{2}, c_{2}\right)$ & $\gamma_{3} P_{3}-M_{9}-T_{g}-\beta_{1} L_{1}-\beta_{2} L_{2}-\alpha I$ & $\theta R-\tau R-C_{A}+R_{A_{3}}-C_{A_{3}}+\beta_{1} L_{1}-\gamma_{3} P_{3}-S$ & $(1-\theta) R+\tau R-C_{B}-G_{B}+\beta_{2} L_{2}-S$ \\
\hline$\left(a_{3}, b_{3}, c_{3}\right)$ & $R_{g_{2}}-\alpha I$ & $\theta(R-\tau R)+\xi \tau R-C_{A}-G_{A}+\lambda \theta R+S$ & $(1-\theta)(R-\tau R)+(1-\xi) \tau R-C_{B}-G_{B}+\varphi(1-\theta) R$ \\
\hline$\left(a_{4}, b_{4}, c_{4}\right)$ & $-C_{g}-T_{g}-\alpha I$ & $\theta R-\tau R-C_{A}+R_{A_{3}}-C_{A_{3}}-S$ & $(1-\theta) R+\tau R-C_{B}-G_{B}-S$ \\
\hline$\left(a_{5}, b_{5}, c_{5}\right)$ & $\gamma_{2} P_{2}-M_{g}-T_{g}-\beta_{1} L_{1}-\beta_{2} L_{2}-\alpha I$ & $\theta R+\tau R-C_{A}-G_{A}+\beta_{1} L_{1}-L_{A}-S$ & $(1-\theta) R-\tau R-C_{B}+R_{B_{3}}-C_{B_{3}}+\beta_{2} L_{2}-\gamma_{2} P_{2}-S$ \\
\hline$\left(a_{6}, b_{6}, c_{6}\right)$ & $2 \gamma_{1} P_{1}-M_{9}-T_{g}-\beta_{1} L_{1}-\beta_{2} L_{2}-\alpha I$ & $\theta R-C_{A}+R_{A 3}-C_{A_{3}}+\beta_{1} L_{1}-\gamma_{1} P_{1}$ & $(1-\theta) R-C_{B}+R_{B_{3}}-C_{B_{3}}+\beta_{2} L_{2}-\gamma_{1} P_{1}$ \\
\hline$\left(a_{7}, b_{7}, c_{7}\right)$ & $-C_{g}-T_{g}-\alpha I$ & $\theta R+\tau R-C_{A}-G_{A}-L_{A}-S$ & $(1-\theta) R-\tau R-C_{B}+R_{B_{3}}-C_{B_{3}}-S$ \\
\hline$\left(a_{8}, b_{8}, c_{8}\right)$ & $-C_{g}-T_{g}-\alpha I$ & $\theta R-C_{A}$ & $(1-\theta) R-C_{B}$ \\
\hline
\end{tabular}

According to Friedman's hypothesis of rationality (Friedman, D 1998), the government and member enterprises can obtain 243 corresponding profit by adopting different stategies and establish the replication dynamic equations.

\subsubsection{Evolutionary Stabilization Strategy of Government}

Suppose that when government chooses "incentive" strategy, its expected profit is $U_{g_{1}}$; when government chooses "non-incentive" strategy, its expected profit is $U_{g_{2}}$. The average expected profit for government is $U_{\mathrm{g}}$.

$$
\begin{aligned}
U_{\mathrm{g} 1} & =\left(R_{\mathrm{g} 1}-M_{\mathrm{g}}-\beta_{1} L_{1}-\beta_{2} L_{2}-\alpha I\right) y z+\left(\gamma_{3} P_{3}-M_{\mathrm{g}}-T_{g}-\beta_{1} L_{1}-\beta_{2} L_{2}-\alpha I\right)(1-y) z \\
& +\left(\gamma_{2} P_{2}-M_{\mathrm{g}}-T_{g}-\beta_{1} L_{1}-\beta_{2} L_{2}-\alpha I\right) y(1-z)+\left(2 \gamma_{1} P_{1}-M_{\mathrm{g}}-T_{g}-\beta_{1} L_{1}-\beta_{2} L_{2}-\alpha I\right)(1-y)(1-z) \\
& =y z R_{\mathrm{g} 1}+(1-y) z \gamma_{3} P_{3}+y(1-z) \gamma_{2} P_{2}+2(1-y-z+y z) \gamma_{1} P_{1}+(y z-1) T_{g}-M_{\mathrm{g}}-\beta_{1} L_{1}-\beta_{2} L_{2}-\alpha I
\end{aligned}
$$

$$
\begin{aligned}
U_{\mathrm{g} 2} & =\left(R_{\mathrm{g} 2}-\alpha I y z+\left(-C_{g}-T_{g}-\alpha I\right)(1-y) z+\left(-C_{g}-T_{g}-\alpha I\right) y(1-z)+\left(-C_{g}-T_{g}-\alpha I\right)(1-y)(1-z)\right. \\
& =y z\left(R_{\mathrm{g} 2}+C_{g}+T_{g}\right)-C_{g}-T_{g}-\alpha I
\end{aligned}
$$

$$
U_{\mathrm{g}=x} U_{\mathrm{g} 1}+(1-x) U_{\mathrm{g} 2}
$$

The replication dynamic equation of probability of "incentive" strategy selected by the government is as follows:

$$
\begin{aligned}
F(x)= & \frac{\mathrm{d} x}{d t}=x\left(U_{g_{1}}-U_{g}\right)=x(1-x)\left[(1-y) z \gamma_{3} P_{3}+y(1-z) \gamma_{2} P_{2}+2(1-y-z+y z) \gamma_{1} P_{1}\right. \\
& \left.-M g-\beta_{1} L_{1}-\beta_{2} L_{2}-(y z-1) C_{g}+y z\left(R_{g_{1}}-R_{g_{2}}\right)\right]
\end{aligned}
$$

The partial derivative of the replication dynamic equation $F(x)$ can be obtained as follows:

$$
F^{\prime}(x)=(1-2 x)\left[(1-y) z \gamma_{3} P_{3}+y(1-z) \gamma_{2} P_{2}+2(1-y-z+y z) \gamma_{1} P_{1}-M g-\beta_{1} L_{1}-\beta_{2} L_{2}-(y z-1) C_{g}+y z\left(R_{g_{1}}-R_{g^{2}}\right)\right]
$$

According to the stability theorem for differential equation, the probability that the government chooses "incentive" strategy in a stable state must satisfy: $F(x)=0$ and $\frac{d F(x)}{d x}<0$. According to formula (5),

$$
(1-y) z \gamma_{3} P_{3}+y(1-z) \gamma_{2} P_{2}+2(1-y-z+y z) \gamma_{1} P_{1}-M g-\beta_{1} L_{1}-\beta_{2} L_{2}-(y z-1) C_{g}+y z\left(R_{g_{1}}-R_{g_{2}}\right)=0
$$


indicates the boundary of the stable state, then $y=\frac{-C_{g}+\beta_{1} L_{1}+\beta_{2} L_{2}+M_{g}-2 \gamma_{1} P_{1}-\left(\gamma_{3} P_{3}-2 \gamma_{1} P_{1}\right) z}{\gamma_{2} P_{2}-2 \gamma_{1} P_{1}-\left(\gamma_{2} P_{2}+\gamma_{3} P_{3}-2 \gamma_{1} P_{1}+C_{g}-R_{g 1}+R_{g 2}\right) z}$. This shows that all levels are in a stable state, and the proportion of strategy selection does not change with time.

$$
\begin{aligned}
& \text { If } y>\frac{-C_{g}+\beta_{1} L_{1}+\beta_{2} L_{2}+M_{g}-2 \gamma_{1} P_{1}-\left(\gamma_{3} P_{3}-2 \gamma_{1} P_{1}\right) z}{\gamma_{2} P_{2}-2 \gamma_{1} P_{1}-\left(\gamma_{2} P_{2}+\gamma_{3} P_{3}-2 \gamma_{1} P_{1+} C_{g}-R_{g_{1}}+R_{g_{2}}\right) z} \text {, that is: } \\
& \quad(1-y) z \gamma_{3} P_{3}+y(1-z) \gamma_{2} P_{2}+2(1-y-z+y z) \gamma_{1} P_{1}-M g-\beta_{1} L_{1}-\beta_{2} L_{2}-(y z-1) C_{g}+y z\left(R_{g_{1}}-R_{g_{2}}\right)>0 .
\end{aligned}
$$

Now $F^{\prime}(x=0)>0, F^{\prime}(x=1)<0$, then $x^{*}=1$ indicates that the "incentive" is a stable state, while the "non-incentive" is an unstable state.

$$
\begin{aligned}
& \text { If } y<\frac{-C_{g}+\beta_{1} L_{1}+\beta_{2} L_{2}+M_{g}-2 \gamma_{1} P_{1}-\left(\gamma_{3} P_{3}-2 \gamma_{1} P_{1}\right) z}{\gamma_{2} P_{2}-2 \gamma_{1} P_{1}-\left(\gamma_{2} P_{2}+\gamma_{3} P_{3}-2 \gamma_{1} P_{1}+C_{g}-R_{g 1}+R_{g}\right) z} \text {, that is: } \\
& \quad(1-y) z \gamma_{3} P_{3}+y(1-z) \gamma_{2} P_{2}+2(1-y-z+y z) \gamma_{1} P_{1}-M g-\beta_{1} L_{1}-\beta_{2} L_{2}-(y z-1) C_{g}+y z\left(R_{g_{1}}-R_{g_{2}}\right)<0 .
\end{aligned}
$$

Now $F^{\prime}(x=0)<0, F^{\prime}(x=1)>0$, then $x^{*}=0$ indicates that the "non-incentive" is a stable state, while the "incentive" is an unstable state.

The evolutionary phase diagram of the strategy stability of the government depends on the shape of the quadratic curve:

$$
(1-y) z \gamma_{3} P_{3}+y(1-z) \gamma_{2} P_{2}+2(1-y-z+y z) \gamma_{1} P_{1}-M g-\beta_{1} L_{1}-\beta_{2} L_{2}-(y z-1) C_{g}+y z\left(R_{g_{1}}-R_{g^{2}}\right)=0
$$

\subsubsection{Evolutionary Stabilization Strategy of Enterprise A}

Suppose that when enterprise A chooses "positive cooperation" strategy, its expected profit is $U_{\mathrm{A}^{*}}$; when enterprise A chooses "negative cooperation" strategy, its expected profit is $U_{\mathrm{A}_{2}}$. The average expected profit for enterprise A is $U_{\mathrm{A}}$.

$$
\begin{aligned}
U_{A_{1}}= & \left(\theta(R-\tau R)+\xi \tau R-C_{A}-G_{A}+\lambda \theta R+\beta_{1} L_{1}+S\right) x z+\left(\theta(R-\tau R)+\xi \tau R-C_{A}-G_{A}+\lambda \theta R+S\right)(1-x) z \\
& +\left(\theta R+\tau R-C_{A}-G_{A}+\beta_{1} L_{1}-L_{A}-S\right) x(1-z)+\left(\theta R+\tau R-C_{A}-G_{A}-L_{A}-S\right)(1-x)(1-z) \\
& =z((\xi-\theta-1) \tau R+\lambda \theta R)+x \beta_{1} L_{1}+\theta R+\tau R-C_{A}-G_{A}-L_{A}+(2 z-1) S \\
U_{A_{2}}= & \left(\theta R-\tau R-C_{A}+R_{A_{3}}-C_{A_{3}}+\beta_{1} L_{1}-\gamma_{3} P_{3}-S\right) x z+\left(\theta R-\tau R-C_{A}+R_{A_{3}}-C_{A_{3}}-S\right)(1-x) z \\
& +\left(\theta R-C_{A}+R_{A_{3}}-C_{A_{3}}+\beta_{1} L_{1}-\gamma_{1} P_{1}\right) x(1-z)+\left(\theta R-C_{A}\right)(1-x)(1-z) \\
& =-x z \gamma_{3} P_{3}+(x-z-x z) R_{A_{3}}+(x z-x-z) C_{A_{3}}-z S+x \beta_{1} L_{1}+x(z-1) \gamma_{1} P_{1+} \theta R-C_{A}-z \tau R
\end{aligned}
$$

$$
U_{\mathrm{A}=\mathrm{y}} U_{\mathrm{A} 1}+(1-\mathrm{y}) U_{\mathrm{A} e}
$$

The replication dynamic equation of probability of "positive cooperarion" strategy selected by member enterprise A is as follows:

$$
\begin{aligned}
F(y)= & \frac{\mathrm{d} y}{d t}=x\left(U_{A_{1}}-U_{A}\right)=y(1-y)\left[z \xi \tau R-z \theta \tau R+z \lambda \theta R+3 z S+\tau R-G_{A}-L_{A}-S+x z \gamma_{3} P_{3}\right. \\
& \left.-(x-z-x z)\left(R_{A_{3}}+C_{A 3}\right)-x(z-1) \gamma_{1} P_{1}\right]
\end{aligned}
$$

$$
F^{\prime}(y)=(1-2 y)\left[z \xi \tau R-z \theta \tau R+z \lambda \theta R+3 z S+\tau R-G_{A}-L_{A}-S+x z \gamma_{3} P_{3}-(x-z-x z)\left(R_{A_{3}}+C_{A_{3}}\right)-x(z-1) \gamma_{1} P_{1}\right]
$$

According to the stability theorem for differential equation, the probability that member enterprise A chooses "positive cooperation" strategy in a stable state must satisfy: $F(y)=0$ and $\frac{d F(y)}{d y}<0$. According to formula (13),

$$
z \xi \tau R-z \theta \tau R+z \lambda \theta R+3 z S+\tau R-G_{A}-L_{A}-S+x z \gamma_{3} P_{3}-(x-z-x z)\left(R_{A_{3}}+C_{A_{3}}\right)-x(z-1) \gamma_{1} P_{1}=0
$$

indicates the boundary of the stable state, then $z=\frac{S+L_{A}+G_{A}-\tau R-\left(\gamma_{1} P_{1}-R_{A_{3}}+C_{A_{3}}\right) x}{(\xi-\theta) \tau R+\lambda \theta R+3 S+R_{A 3}+C_{A_{3}}+\left(\gamma_{3} P_{3}+R_{A_{3}}-C_{A_{3}}-\gamma_{1} P_{1}\right) x}$.

$$
\text { If } z>\frac{S+L_{A}+G_{A}-\tau R-\left(\gamma_{1} P_{1}-R_{A_{3}}+C_{A_{3}}\right) x}{(\xi-\theta) \tau R+\lambda \theta R+3 S+R_{A_{3}}+C_{A_{3}}+\left(\gamma_{3} P_{3}+R_{A_{3}}-C_{A_{3}}-\gamma_{1} P_{1}\right) x} \text {, that is: }
$$




$$
z \xi \tau R-z \theta \tau R+z \lambda \theta R+3 z S+\tau R-G_{A}-L_{A}-S+x z \gamma_{3} P_{3}-(x-z-x z)\left(R_{A_{3}}+C_{A 3}\right)-x(z-1) \gamma_{1} P_{1}>0
$$

Now $F^{\prime}(y=0)>0, F^{\prime}(y=1)<0$, then $y^{*}=1$ indicates that the "positive cooperation" is a stable state, while the "negative cooperation" is an unstable state.

$$
\begin{aligned}
& \text { If } z<\frac{S+L_{A}+G_{A}-\tau R-\left(\gamma_{1} P_{1}-R_{A_{3}}+C_{A_{3}}\right) x}{(\xi-\theta) \tau R+\lambda \theta R+3 S+R_{A_{3}}+C_{A_{3}}+\left(\gamma_{3} P_{3}+R_{A_{3}}-C_{A_{3}}-\gamma_{1} P_{1}\right) x} \text {, that is: } \\
& z \xi \tau R-z \theta \tau R+z \lambda \theta R+3 z S+\tau R-G_{A}-L_{A}-S+x z \gamma_{3} P_{3}-(x-z-x z)\left(R_{A_{3}}+C_{A_{3}}\right)-x(z-1) \gamma_{1} P_{1}<0
\end{aligned}
$$

Now $F^{\prime}(y=0)<0, F^{\prime}(y=1)>0$, then $y^{*}=0$ indicates that the "negative cooperation" is a stable state, while the "positive cooperation" is an unstable state.

The evolution phase diagram of the strategic stability of member enterprise A depends on the shape of the quadratic curve: $z \xi \tau R-z \theta \tau R+z \lambda \theta R+3 z S+\tau R-G_{A}-L_{A}-S+x z \gamma_{3} P_{3}-(x-z-x z)\left(R_{A_{3}}+C_{A_{3}}\right)-x(z-1) \gamma_{1} P_{1}=0$

\subsubsection{Evolutionary Stabilization Strategy of Enterprise B}

Suppose that when enterprise B chooses "positive cooperation" strategy, its expected profit is $U_{\mathrm{B}}$; when enterprise B chooses "negative cooperation" strategy, its expected profit is $U_{\mathrm{B}}$. The average expected profit for enterprise $\mathrm{B}$ is $U_{\mathrm{B}}$.

$$
\begin{aligned}
U_{\mathrm{B}} & =\left((1-\theta)(R-\tau R)+(1-\xi) \tau R-C_{B}-G_{B}+\varphi(1-\theta) R+\beta_{2} L_{2}+S\right) x y+\left((1-\theta) R+\tau R-C_{B}-G_{B}+\beta_{2} L_{2}-S\right)(1-y) x \\
& +\left((1-\theta)(R-\tau R)+(1-\xi) \tau R-C_{B}-G_{B}+\varphi(1-\theta) R+S\right) y(1-x)+\left((1-\theta) R+\tau R-C_{B}-G_{B}-S\right)(1-x)(1-y) \\
& =x \beta_{2} L_{2}-y(1-\theta) \tau R+y(1-\xi) \tau R+y \varphi(1-\theta) R-y \tau R+(2 y-1) S+(1-\theta) R+\tau R-C_{B}-G_{B}
\end{aligned}
$$

$$
\begin{aligned}
U_{\mathrm{B}}= & \left((1-\theta) R-\tau R-C_{B}+R_{B 3}-C_{B 3}+\beta_{2} L_{2}-\gamma_{2} P_{2}-S\right) x y+\left((1-\theta) R-C_{B}+R_{B 3}-C_{B 3}+\beta_{2} L_{2}-\gamma_{1} P_{1}\right)(1-y) x \\
& +\left((1-\theta) R-\tau R-C_{B}+R_{B 3}-C_{B 3}-S\right) y(1-x)+\left((1-\theta) R-C_{B}\right)(1-x)(1-y) \\
& =x y\left(\gamma_{1} P_{1}-\gamma_{2} P_{2}-R_{B 3}+C_{B 3}\right)+x\left(R_{B 3}-C_{B 3}+\beta_{2} L_{2}-\gamma_{1} P_{1}\right)+y\left(R_{B_{3}}-C_{B_{3}}-S-\tau R\right)+(1-\theta) R-C_{B}
\end{aligned}
$$

The replication dynamic equation of probability of "positive cooperarion" strategy selected by the enterprise B is as follows:

$$
\begin{aligned}
F(z)= & \frac{\mathrm{d} z}{d t}=z\left(U_{B_{1}}-U_{B}\right)=z(1-z)[-y(1-\theta) \tau R+y(1-\xi) \tau R+y \varphi(1-\theta) R+(3 y-1) S+\tau R \\
& \left.-G_{B}-x y\left(\gamma_{1} P_{1}-\gamma_{2} P_{2}-R_{B_{3}}+C_{B_{3}}\right)-x\left(R_{B_{3}}-C_{B_{3}}-\gamma_{1} P_{1}\right)-y\left(R_{B_{3}}-C_{B_{3}}\right)\right]
\end{aligned}
$$

The partial derivative of the replication dynamic equation $F(z)$ can be obtained as follows:

$$
\begin{aligned}
F^{\prime}(z)= & (1-2 z)[-y(1-\theta) \tau R+y(1-\xi) \tau R+y \varphi(1-\theta) R+(3 y-1) S+\tau R \\
& \left.-G_{B}-x y\left(\gamma_{1} P_{1}-\gamma_{2} P_{2}-R_{B 3}+C_{B 3}\right)-x\left(R_{B 3}-C_{B 3}-\gamma_{1} P_{1}\right)-y\left(R_{B 3}-C_{B 3}\right)\right]
\end{aligned}
$$

According to the stability theorem for differential equation, the probability of member enterprise B choosing "positive cooperation" strategy in a stable state must satisfy: $F(z)=0$ and $\frac{d F(z)}{d z}<0$. According to formula (21),

indicates the boundary of the stable state, then $x=\frac{\tau R-S-G_{B}+\left[(\theta-\xi) \tau R+\varphi(1-\theta) R+3 S-R_{A 3}+C_{B 3}\right] y}{R_{B 3}-C_{B 3}-\gamma_{1} P_{1}+\left(\gamma_{1} P_{1}-\gamma_{2} P_{2}-R_{B 3}+C_{B 3}\right) y}$. 
Now $F^{\prime}(z=0)<0, F^{\prime}(z=1)>0$, then $z^{*}=0$ indicates that "negative cooperation" is in a stable state, while the "positive cooperation" is in an unstable state.

$$
\begin{aligned}
& \text { If } x<\frac{\tau R-S-G_{B}+\left[(\theta-\xi) \tau R+\varphi(1-\theta) R+3 S-R_{A_{3}}+C_{B_{3}}\right] y}{R_{B_{3}}-C_{B 3}-\gamma_{1} P_{1}+\left(\gamma_{1} P_{1}-\gamma_{2} P_{2}-R_{B 3}+C_{B 3}\right) y}, \text { that is: } \\
& -y(1-\theta) \tau R+y(1-\xi) \tau R+y \varphi(1-\theta) R+(3 y-1) S+\tau R-G_{B}-x y\left(\gamma_{1} P_{1}-\gamma_{2} P_{2}-R_{B_{3}}+C_{B 3}\right)-x\left(R_{B_{3}}-C_{B_{3}}-\gamma_{1} P_{1}\right)-y\left(R_{B_{3}}-C_{B_{3}}\right)>0
\end{aligned}
$$

Now $F^{\prime}(z=0)>0, F^{\prime}(z=1)<0$, then $z^{*}=1$ indicates that "positive cooperation" is in a stable state, while the "negative cooperation" is in an unstable state.

The evolution phase diagram of the strategic stability of member enterprise B depends on the shape of the quadratic curve: $-y(1-\theta) \tau R+y(1-\xi) \tau R+y \varphi(1-\theta) R+(3 y-1) S+\tau R-G_{B}-x y\left(\gamma_{1} P_{1}-\gamma_{2} P_{2}-R_{B 3}+C_{B 3}\right)-x\left(R_{B_{3}}-C_{B_{3}}-\gamma_{1} P_{1}\right)-y\left(R_{B_{3}}-C_{B_{3}}\right)=0$

In order to find the equilibrium points of this evolutionary game, three equations are simultaneously established: $F(x)=$ $0, F(y)=0, F(z)=0$, it can be found that there are eight three-species pure strategy equilibrium points: $E_{1}(0,0,0), E_{2}(0,0,1)$, $E_{3}(0,1,0), E_{4}(1,0,0), E_{5}(1,1,0), E_{6}(0,1,1), E_{7}(1,0,1), E_{8}(1,1,1)$. These equilibrium points are located at the boundary of the solution domain of the evolutionary game, and the enclosed area $\Omega$ is called the equilibrium solution domain of the tripartite game. Under normal circumstances, there may also be pure strategy equilibrium points adopted by a single species: $E_{9}\left(0, y_{1}, z_{1}\right), E_{10}\left(1, y_{2}, z_{2}\right), E_{11}\left(x_{1}, 0, z_{3}\right), E_{12}\left(x_{2}, 1, z_{4}\right), E_{13}\left(x_{3}, y_{3}, 0\right), E_{14}\left(x_{4}, y_{4}, 1\right)$ and the equilibrium solution $\left(x^{*}, y^{*}, z^{*}\right)$ that satisfies equations (6) (14) (22).

The stable equilibrium points of the game can be judged by Jacobian matrix (Friedman D 1991). The Jacobian matrix is as follows:

$$
J=\left[\begin{array}{rrr}
\partial F(x) / \partial x & \partial F(x) / \partial y & \partial F(x) / \partial z \\
\partial F(y) / \partial x & \partial F(y) / \partial y & \partial F(y) / \partial z \\
\partial F(z) / \partial x & \partial F(z) / \partial y & \partial F(z) / \partial z
\end{array}\right], \text { in which }
$$

$\partial F(x) / \partial x=(1-2 x)\left[(1-y) z \gamma_{3} P_{3}+y(1-z) \gamma_{2} P_{2}+2(1-y-z+y z) \gamma_{1} P_{1}-M g-\beta_{1} L_{1}-\beta_{2} L_{2}-(y z-1) C_{g}+y z\left(R_{g_{1}}-R_{g_{2}}\right)\right]$

$\partial F(x) / \partial y=x(1-x)\left[-z \gamma_{3} P_{3}+(1-z) \gamma_{2} P_{2}+2(z-1) \gamma_{1} P_{1}-z C_{g}+z R_{g_{1}}-z R_{g_{2}}\right]$

$\partial F(x) / \partial z=x(1-x)\left[(1-y) \gamma_{3} P_{3}-y \gamma_{2} P_{2}+2(y-1) \gamma_{1} P_{1}-y C_{g}+y R_{g_{1}}-y R_{g_{2}}\right]$

$\partial F(y) / \partial x=y(1-y)\left[y \gamma_{3} P_{3}+(z-1)\left(R_{A_{3}}-C_{A 3}-\gamma_{1} P_{1}\right)\right]$

$\partial F(y) / \partial y=(1-2 y)\left[z \xi \tau R-z \theta \tau R+z \lambda \theta R+3 z S+\tau R-G_{A}-L_{A}-S+x z \gamma_{3} P_{3}-(x-z-x z)\left(R_{A 3}+C_{A 3}\right)-x(z-1) \gamma_{1} P_{1}\right]$

$\partial F(y) / \partial z=y(1-y)\left[\xi \tau R-\theta \tau R+\lambda \theta R+3 S+R_{A_{3}}+C_{A_{3}}+x\left(R_{A 3}-C_{A_{3}}-\gamma_{1} P_{1}\right)\right]$

$\partial F(z) / \partial x=z(1-z)\left[-y\left(\gamma_{1} P_{1}-\gamma_{2} P_{2}-R_{B_{3}}+C_{B_{3}}\right)-R_{B_{3}}+C_{B_{3}}+\gamma_{1} P_{1}\right]$

$\partial F(z) / \partial y=z(1-z)\left[(\theta-\xi) \tau R+\varphi(1-\theta) R+3 S+x\left(\gamma_{1} P_{1}-\gamma_{2} P_{2}-R_{B_{3}}+C_{B_{3}}\right)-R_{B_{3}}+C_{B_{3}}\right]$

$\partial F(z) / \partial z=(1-2 z)\left[-y(1-\theta) \tau R+y(1-\xi) \tau R+y \varphi(1-\theta) R+(3 y-1) S+\tau R-G_{B}\right.$

$$
\left.-x y\left(\gamma_{1} P_{1}-\gamma_{2} P_{2}-R_{B 3}+C_{B 3}\right)-x\left(R_{B 3}-C_{B 3}-\gamma_{1} P_{1}\right)-y\left(R_{B 3}-C_{B 3}\right)\right]
$$

According to Lyapunov's first rule: if all eigenvalues of the Jacobian matrix have negative real parts, then the equilibrium point is an asymptotically stable point. If all eigenvalues of the Jacobian matrix have positive real parts, then the equilibrium point is an unstable point. If the eigenvalues of the Jacobian matrix have both positive real parts and negative real parts, then the equilibrium point is also an unstable point. If the eigenvalues of the Jacobian matrix have both zero real parts and negative real parts, the equilibrium point is in a critical state, and the stability cannot be determined by the symbol of the eigenvalue.

The stability of the tripartite evolutionary game system can be studied only by discussing the stability of the eight three-species pure strategy equilibrium points, and the rest are in non-asymptotically stable states. Eight three-species pure strategy equilibrium points were substituted into the Jacobian matrix to analyze the stability of each equilibrium point. The results are shown in Table 3 below.

Table 3. Stability analysis of each equilibrium point. 
Table 4. The Values of Each Parameter (a).

\begin{tabular}{cccccccccccccccccc}
\hline $\boldsymbol{R}_{\boldsymbol{g}_{\mathbf{1}}}$ & $\boldsymbol{R}_{\boldsymbol{g}_{\mathbf{2}}}$ & $\boldsymbol{C}_{\boldsymbol{g}}$ & $\boldsymbol{T}_{\boldsymbol{g}}$ & $\boldsymbol{M}_{\boldsymbol{g}}$ & $\boldsymbol{\beta}_{\boldsymbol{1}}$ & $\boldsymbol{L}_{\boldsymbol{1}}$ & $\boldsymbol{\beta}_{\mathbf{2}}$ & $\boldsymbol{L}_{\boldsymbol{2}}$ & $\boldsymbol{\gamma}_{\mathbf{1}}$ & $\boldsymbol{P}_{\boldsymbol{1}}$ & $\boldsymbol{\gamma}_{\mathbf{2}}$ & $\boldsymbol{P}_{\mathbf{2}}$ & $\boldsymbol{\gamma}_{\mathbf{3}}$ & $\boldsymbol{P}_{\mathbf{3}}$ & $\boldsymbol{\alpha}$ & $\boldsymbol{I}$ \\
\hline 150 & 25 & 120 & 125 & 40 & 0.5 & 60 & 0.5 & 70 & 0.5 & 85 & 0.5 & 75 & 0.5 & 80 & 0.5 & 70 \\
\hline
\end{tabular}

Table 4. The Values of Each Parameter (b).

\begin{tabular}{cccccccccccccccccc}
$\boldsymbol{R}_{\boldsymbol{A}_{1}}$ & $\boldsymbol{G}_{\boldsymbol{A}}$ & $\boldsymbol{\theta}$ & $\boldsymbol{R}$ & $\boldsymbol{C}_{\boldsymbol{A}_{\mathbf{2}}}$ & $\boldsymbol{\lambda}$ & $\boldsymbol{R}_{\boldsymbol{A}_{\boldsymbol{3}}}$ & $\boldsymbol{C}_{\boldsymbol{A}_{\boldsymbol{3}}}$ & $\boldsymbol{L}_{\boldsymbol{A}}$ & $\boldsymbol{R}_{\boldsymbol{B}_{\boldsymbol{1}}}$ & $\boldsymbol{G}_{\boldsymbol{B}}$ & $\boldsymbol{C}_{\boldsymbol{B}_{\mathbf{2}}}$ & $\boldsymbol{\varphi}$ & $\boldsymbol{R}_{\boldsymbol{B}_{3}}$ & $\boldsymbol{C}_{\boldsymbol{B}_{3}}$ & $\boldsymbol{S}$ & $\boldsymbol{\tau}$ & $\boldsymbol{\xi}$ \\
\hline 130 & 30 & 0.5 & 190 & 30 & 0.5 & 50 & 45 & 20 & 90 & 30 & 30 & 0.5 & 20 & 15 & 20 & 0.5 & 0.5 \\
\hline
\end{tabular}

(1) The influence of $\beta_{1}$ on the strategy evolution of the tripartite participants

Assign values of $0.2,0.5,0.8$ to $\beta_{1}$, respectively, representing the low, medium, and high intensity of government subsidies and rewards for member enterprise A. The simulation results are shown in Fig. 1. Fig. 1 shows that during the process of system evolution to a stable point, the increase in government subsidies and rewards to member enterprise A can increase the rate of member enterprise A's evolution in the direction of positive cooperation. As $\beta_{1}$ increases, the probability that member enterprise A adopts "positive cooperation" strategy increases and eventually stabilizes at 1 , while the probability that the government converges to "incentives" decreases. This is because the greater the subsidies and rewards that the government gives to member enterprise A, the more cost that member enterprise A promotes the green distribution operations will be compensated, and the faster it will evolve in the direction of positive cooperation. However, the government has to bear significant incentive cost.

(2)The influence of $\beta_{2}$ on the strategy evolution of the tripartite participants

Assign values of $0.2,0.5,0.8$ to $\beta_{2}$, respectively, representing the low, medium, and high intensity of government subsidies and rewards for member enterprise B. The simulation results are shown in Fig. 2. Fig. 2 shows that in the process of system evolution to a stable point, the increase in government subsidies and rewards to member enterprise $\mathrm{B}$ can increase the rate of member enterprise $\mathrm{B}$ evolving in the direction of positive cooperation, especially when $\beta_{2}=0.8$, member enterprise $\mathrm{B}$ tends to cooperate positively at a very fast rate. As $\beta_{2}$ increases, the probability that member enterprise B adopts "positive cooperation" strategy increases and eventually stabilizes at 1 , while the probability that the government converges to "incentives" decreases, or even decreases to zero. This is because the subsidies and rewards the government gives to member enterprise B are far greater than those given to member enterprise A. Although member enterprise B's cost of promoting green distribution operations can be more compensated, thus making it more inclined to cooperate actively, the incentive cost borne by the government is much significant.

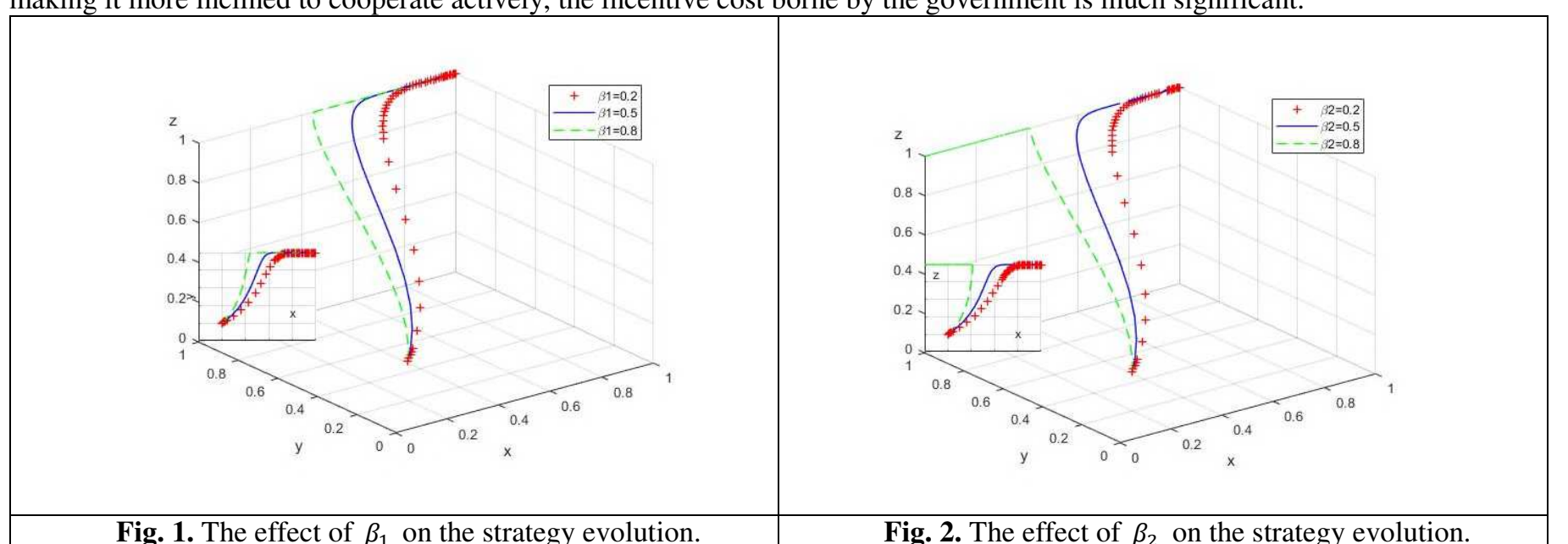

(3)The influence of $\gamma_{1}$ on the strategy evolution of the tripartite participants

Assign values of $0.3,0.5,0.7$ to $\gamma_{1}$, respectively, representing the low, medium, and high intensity of government's punishment on member enterprise B. The simulation results are shown in Fig. 3. Fig. 3 shows that in the process of system evolution to a stable point, the increase in the government's punishment on member enterprise $\mathrm{A} /$ member enterprise $\mathrm{B}$ can reduce the rate of member enterprise $\mathrm{A} / \mathrm{member}$ enterprise $\mathrm{B}$ evolving in the direction of positive cooperation. As $\gamma_{1}$ increases, the probability that member enterprise A/member enterprise B adopts "positive cooperation" strategy increases and eventually stabilizes at 1 , and the probability that the government converges to "incentives" also increases. The reason why the government punishes both member enterprises is that they still cooperate negatively when they are motivated by the government, and the motive of negative cooperation is that both sides conspire to defraud the government subsidies and rewards. Once their speculative activities are discovered, the punishment given by the government will exceed the sum of the subsidies and rewards they have cheated, forcing them to cooperate actively. This is also the reason why when the intensity of punishment increases, the rate at which member enterprise B tends to cooperate positively decreases, but the probability will eventually stabilize at 1 .

(4)The influence of $\gamma_{2}$ on the strategy evolution of the tripartite participants

Assign values of $0.3,0.5,0.7$ to $\gamma_{2}$, respectively, representing the low, medium, and high intensity of the government's punishment of member enterprise B. The simulation results are shown in Fig. 4. Fig. 4 shows that in the process of system evolution to a stable point, the increase of the government's punishment on member enterprise B can reduce the rate of member enterprise B 
evolving in the direction of positive cooperation. As $\gamma_{2}$ increases, the probability that member enterprise B adopts "positive cooperation" strategy increases and eventually stabilizes at 1 , and the probability that the government converges to incentives also increases. The reason why the government punishes member enterprise B is that member enterprise B conducts the "free-riding" behavior on member enterprise A. Once the speculative behavior is discovered, the government will punish the member enterprise $\mathrm{B}$ more than the speculative gains it has obtained, forcing it to cooperate positively. This is also the reason why when the intensity of punishment increases, the rate at which member enterprise B tends to cooperate positively decreases, but the probability will eventually stabilize at 1 .

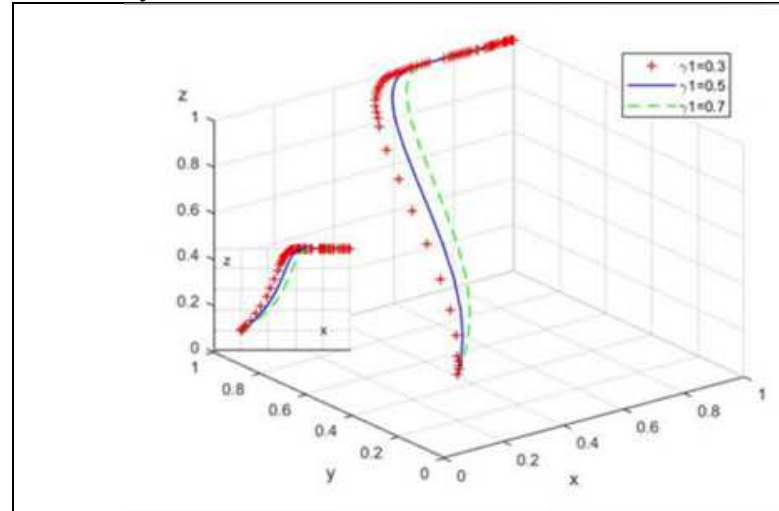

Fig. 3. The effect of $\gamma_{1}$ on the strategy evolution.

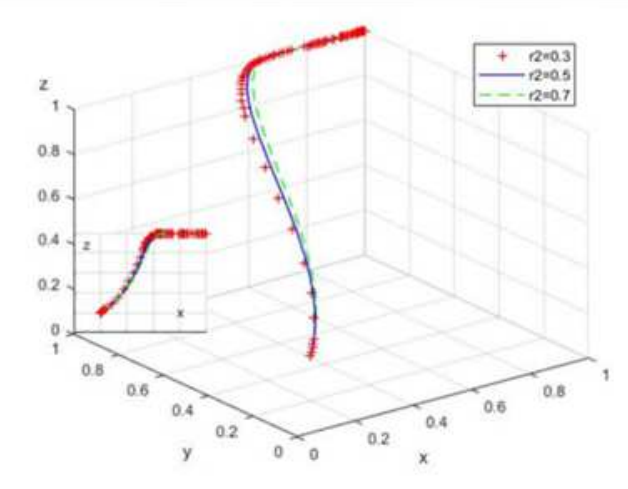

Fig. 4. The effect of $\gamma_{2}$ on the strategy evolution.

(5)The influence of $\gamma_{3}$ on the strategy evolution of the tripartite participants

Assign values of $0.3,0.5,0.7$ to $\gamma_{3}$, respectively, representing the low, medium, and high intensity of the government's punishment of member enterprise A. The simulation results are shown in Fig. 5. Fig. 5 shows that in the process of system evolution to a stable point, the increase in the government's punishment on member enterprise A can reduce the rate of member enterprise A's evolution in the direction of positive cooperation. As $\gamma_{3}$ increases, the probability that member enterprise A adopts "positive cooperation" strategy increases and eventually stabilizes at 1 , and the probability of government convergence to "incentives" does not change significantly. The reason why the government punishes the member enterprise A is that member enterprise A takes advantage of information asymmetry to defraud the government subsidies and rewards. Once the speculative behavior is discovered, the punishment imposed by the government will exceed the speculative gains it has obtained, forcing it to cooperate positively. This is also the reason why when the intensity of punishment increases, the rate at which member enterprise A tends to cooperate positively decreases, but the probability will eventually stabilize at 1 .

(6)The influence of $L_{A}$ on the strategy evolution of the tripartite participants

Assign values of 0, 20, 40 to $L_{A}$, and the simulation results are shown in Fig. 6. Fig. 6 shows that in the process of system evolution to a stable point, the increase in the additional losses suffered by member enterprise A can reduce the rate of its evolution toward positive cooperation, and the rate of member enterprise B's evolution toward positive cooperation increases. As $L_{A}$ increases, the probability that member enterprise A adopts "positive cooperation" strategy increases and eventually stabilizes at 1 , and the probability that member enterprise B adopts "positive cooperation" also increases. The change in $L_{A}$ has not changed the trend of member enterprise A choosing to positively cooperate, because the government is also converging to "incentives". The "incentive" strategy adopted by the government includes punishment on member enterprise B, and the penalties obtained from member enterprise B can be transferred to member enterprise A to compensate its losses. In addition, due to the fact that member enterprise B has gradually lost the trust from others and is even at the risk of being removed from the alliance, it has to actively participate in promoting green distribution operations to improve its current poor image from the perspective of long-term benefits, thus its probability of positive cooperation also increases.

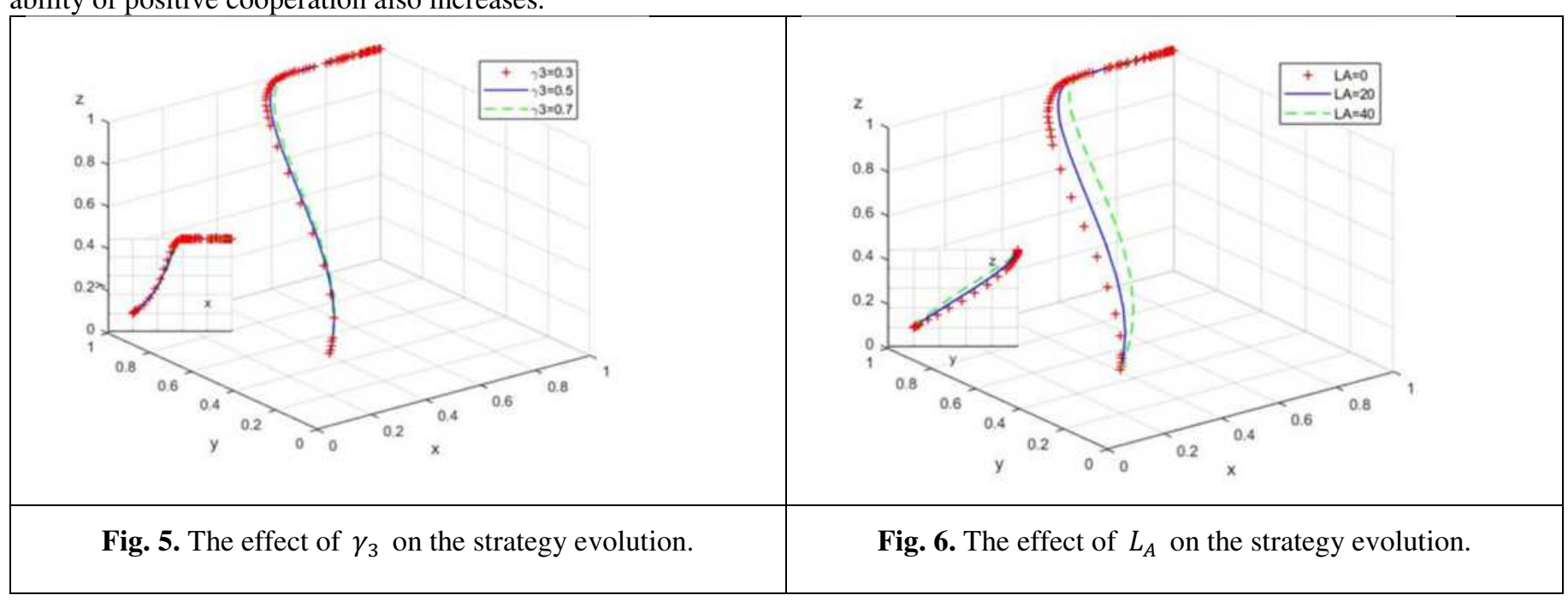


(7)The influence of $G_{A}$ on the strategy evolution of the tripartite participants

Assign values of 5, 30, 55 to $G_{A}$ respectively, and the simulation results are shown in Fig. 7 . Fig. 7 shows that in the process of system evolution to a stable point, the increase in the cost of member enterprise A promoting green distribution operations can reduce the rate at which member enterprise A evolves in the direction of positive cooperation, while the rate at which the government converges to "incentive" strategy increases. As $G_{A}$ increases, the probability of the government adopting "incentive" strategy increases, and the probability of member enterprise A adopting "positive cooperation" strategy will also increase as the probability of the government adopting "incentive" strategy increases, and eventually stabilizes at 1.

(8)The influence of $G_{B}$ on the strategy evolution of the tripartite participants

Assign values of 10, 30, and 50 to the parameters respectively, and the simulation results are shown in Fig. 8 . Fig. 8 shows that in the process of system evolution to a stable point, the increase in the cost of member enterprise B promoting green distribution operations can reduce the rate of member enterprise B's evolution toward positive cooperation, while the rate at which the government converges to "incentive" strategy increases. As $G_{B}$ increases, the probability that the government adopts "incentive" strategy increases, and the probability that member enterprise B adopts "positive cooperation" strategy will also increase as the probability of the government adopting "incentive" strategy increases, and eventually stabilizes at 1.

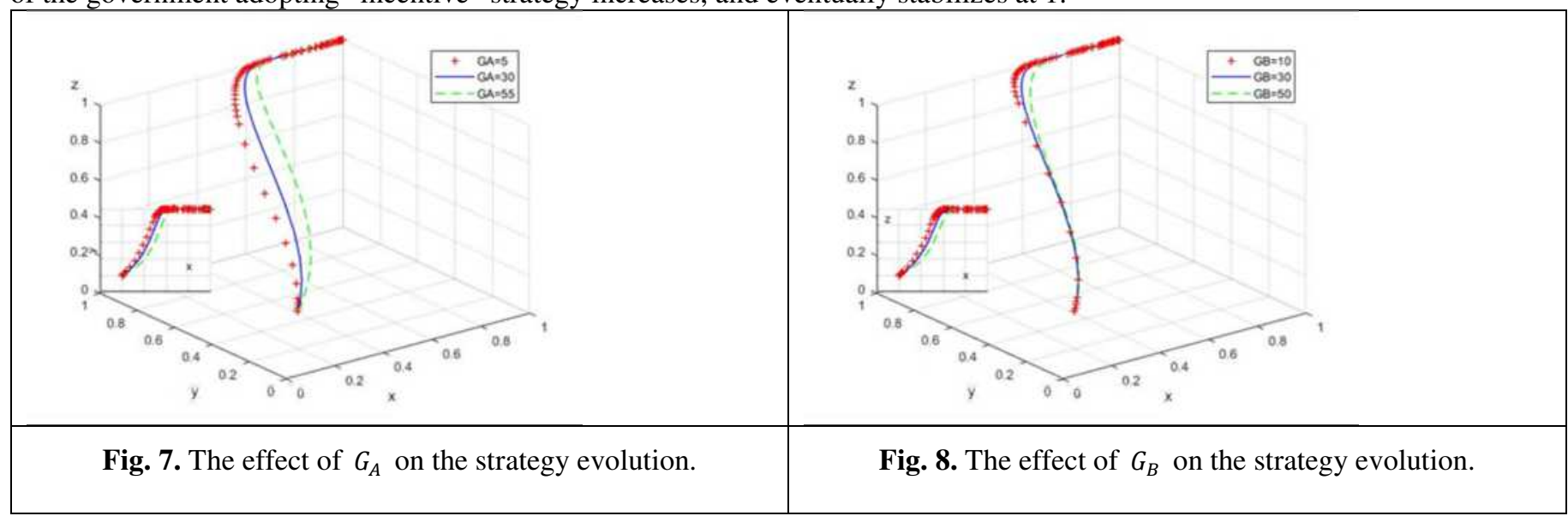

(9)The influence of $\lambda$ on the strategy evolution of the tripartite participants

Assign values of $0.3,0.5,0.7$ to $\lambda$ respectively, and the simulation results are shown in Fig. 9. Fig. 9 shows that in the process of system evolution to a stable point, the increase in member enterprise A's additional benefit coefficient can increase the rate of member enterprise A's evolution in the direction of positive cooperation, while the rate at which the government converges to "incentive" strategy does not change significantly. As $\lambda$ increases, the probability that member enterprise A adopts "positive cooperation" strategy increases and eventually stabilizes at 1 . The probability of the government converging to "incentives" does not change significantly. The size of the additional benefit coefficient does not have a significant impact on whether member enterprise A ultimately chooses to positively cooperate, because the additional benefits is non-monetary (such as the advantages brought by large-scale operations and a good business environment). Therefore, the government needs to play its role in reducing administrative burdens and creating a good market environment for member enterprises, thereby increasing their additional benefits and enhancing their willingness to promote green distribution operations.

(10)The influence of $\varphi$ on the strategy evolution of the tripartite participants

Assign values of $0.3,0.5,0.8$ to $\varphi$ respectively, and the simulation results are shown in Fig. 10. Fig. 10 shows that in the process of system evolution to a stable point, the increase in member enterprise B's additional benefit coefficient can increase the rate of member enterprise B's evolution in the direction of positive cooperation, while the rate at which the government converges to "incentive" strategy does not change significantly. As $\varphi$ increases, the probability of member enterprise B adopting "positive cooperation" strategy increases and eventually stabilizes at 1, while the probability of government adopting "incentive" strategy does not change significantly. The size of the additional benefit coefficient does not have a significant impact on whether member enterprise B ultimately chooses to positively cooperate, and the reason is the same as that of member enterprise A in (9).
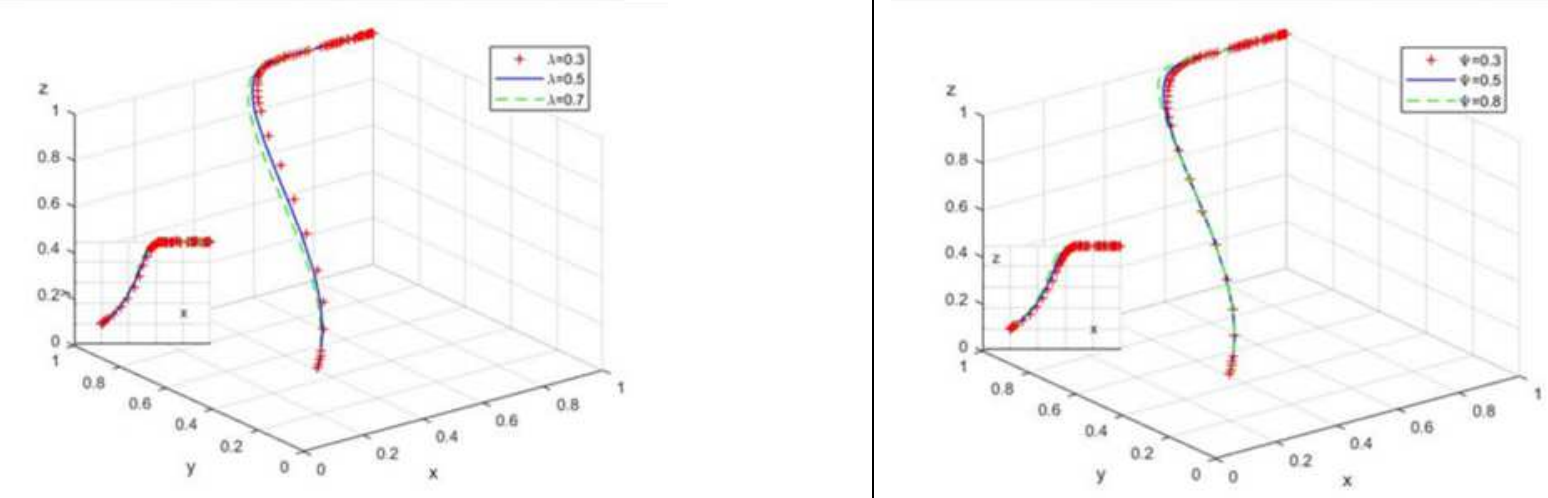
(11)The influence of $R_{A_{3}}$ on the strategy evolution of the tripartite participants

Assign values of $30,50,70$ to $R_{A_{3}}$, and the simulation results are shown in Fig. 11. Fig. 11 shows that in the process of system evolution to a stable point, the change of member enterprise A's speculative gains does not have a significant impact on both the rates at which member enterprise $\mathrm{A}$ tends to positively cooperate and the government tends to incentivize. As $R_{A_{3}}$ increases, the probability of member enterprise A adopting "positive cooperation" strategy and the probability of government adopting "incentive" strategy are not significantly changed. This is because the government and the alliance trust member enterprise A so that its speculative activities are difficult to be detected. In addition, the speculative gains of it will increase linearly with the increase of the government subsidies and rewards, which reveals the bad situation caused by the absence of the necessary supervision mechanism.

(12)The influence of $R_{B_{3}}$ on the strategy evolution of the tripartite participants

Assign values of $0,20,40$ to $R_{B_{3}}$, and the simulation results are shown in Fig. 12. Fig. 12 shows that during the process of system evolution to a stable point, the increase in member enterprise B's speculative gains can reduce the rate of member enterprise B's evolution toward positive cooperation, while the rate at which the government converges to "incentive" strategy increases. As $R_{B_{3}}$ increases, the probability that member enterprise B adopts "positive cooperation" strategy increases and eventually stabilizes at 1 , and the probability that the government converges to "incentives" also increases. The change of $R_{B_{3}}$ does not change the trend of member enterprise B to choose "positive cooperation", and the reason is the same as that of the government's punishment on member enterprise B in (4).

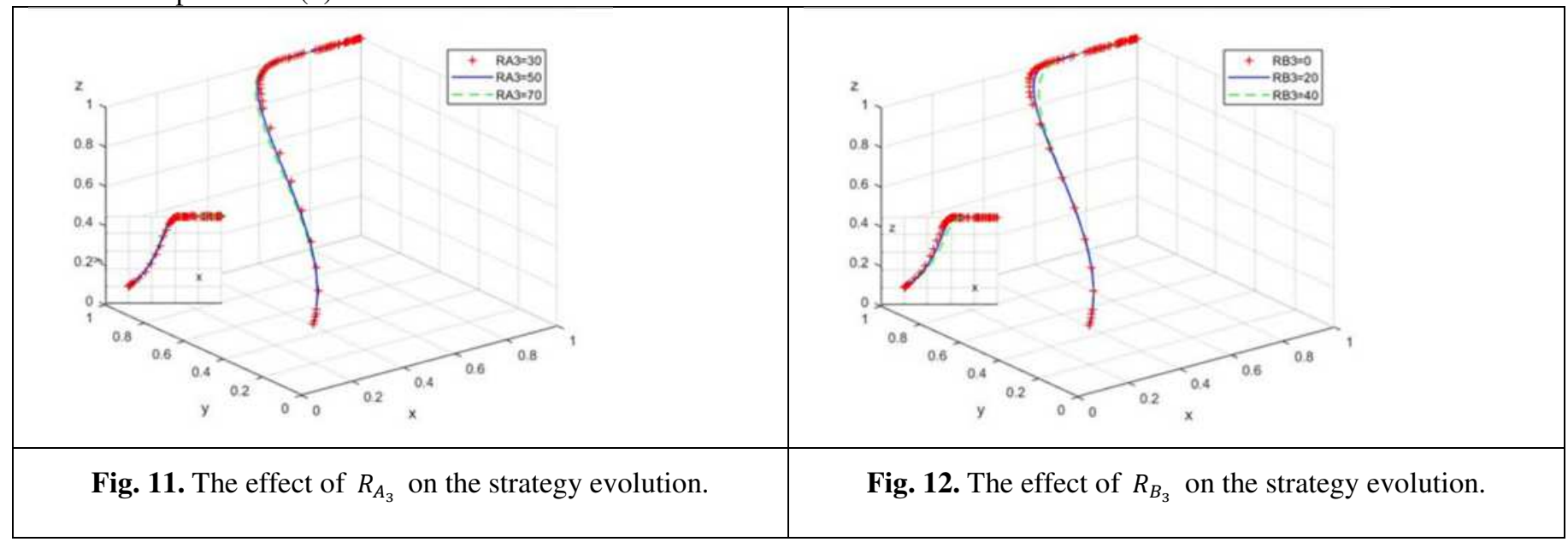

(13)The influence of $\tau$ on the strategy evolution of the tripartite participants

Assign values of $0.1,0.3,0.5$ to $\tau$ respectively, and the simulation results are shown in Fig. 13. Fig. 13 shows that in the process of system evolution to a stable point, the increase in the proportion of the profit caused by environmental benefit factor to the total profit of the alliance can increase the rate at which member enterprises A and B evolve in the direction of positive cooperation. The rate at which the government converges to "incentives" also increases. As $\tau$ increases, the probabilities of member enterprises A and B adopting "positive cooperation" strategy increase and eventually stabilize at 1, and the probability that the government converges to "incentives" also increases. This is because if the environmental benefit factor has a larger weight in the factors affecting the profit distribution, it will encourage member enterprises to participate more actively in the green process of distribution operations and strive for more profit. Meanwhile, the government also needs to introduce preferential policies in time to incentivize them and reduce their risks and costs of green distribution operations.

(14)The influence of $\theta$ on the strategy evolution of the tripartite participants

Assign values of $0.1,0.5,0.9$ to $\theta$ respectively, and the simulation results are shown in Fig. 14. Fig. 14 shows that in the process of system evolution to a stable point, the increase in the proportion of member enterprise A's profit to the total profit $(\theta>0.5)$ can increase the rate of member enterprise A's evolution toward positive cooperation, while the rate at which member enterprise B converges to "positive cooperation" decreases. As $\theta$ increases, the probabilities of the two types of member enterprises adopting "positive cooperation" increase and eventually stabilize at 1 . When $\theta>0.5$, member enterprise A will be more motivated to promote green distribution operations and allocate more profit from within the alliance. Although member enterprise B has a smaller share of the total profit, and its willingness to evolve in the direction of positive cooperation is reduced, it can view the current situation as an opportunity to promote the green transformation of distribution operations and improve the green level of distribution operations in order to occupy a more favorable position in the following profit distribution. Hence they will eventually tend to positively cooperate. It is worth mentioning that the situation of $\theta \leq 0.5$ does not confrom to the characteristic description of member enterprises in the paper.

\section{8}




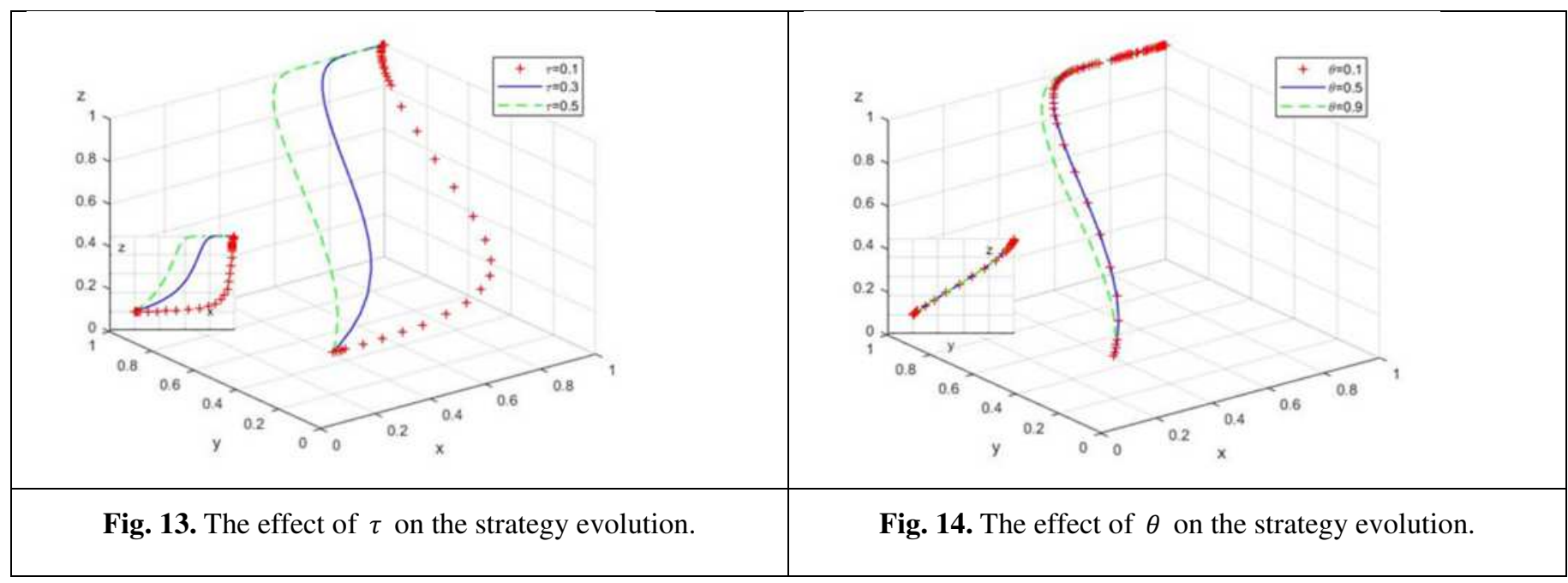

(15)The influence of $\xi$ on the strategy evolution of the tripartite participants

Assign values of $0.3,0.5,0.7$ to $\xi$ respectively, and the simulation results are shown in Fig. 15. Fig. 15 shows that in the process of system evolution to a stable point, the increase in the proportion of member enterprise A's profit to the profit caused by environmental benefit factor can increase the rate of member enterprise A's evolution towards positive cooperation. The increase in the proportion of member enterprise B's profit to the profit caused by environmental benefit factor can increase the rate of member enterprise B's evolution towards positive cooperation. The change of $\xi$ will not change the trend of the two types of enterprises evolving towards positive cooperation, but it will affect the enthusiasm of the two to promote green distribution operations. The more profit caused by environmental benefits factor that a certain member enterprise is allocated, the fewer the other one is allocated. Therefore, the government can guide the latter one to form a benign competition and cooperation relationship with the former one, encourage it to exert the effect of "learning by doing" in the process of cooperation, so as to learn more from the former one in promoting green distribution operations.

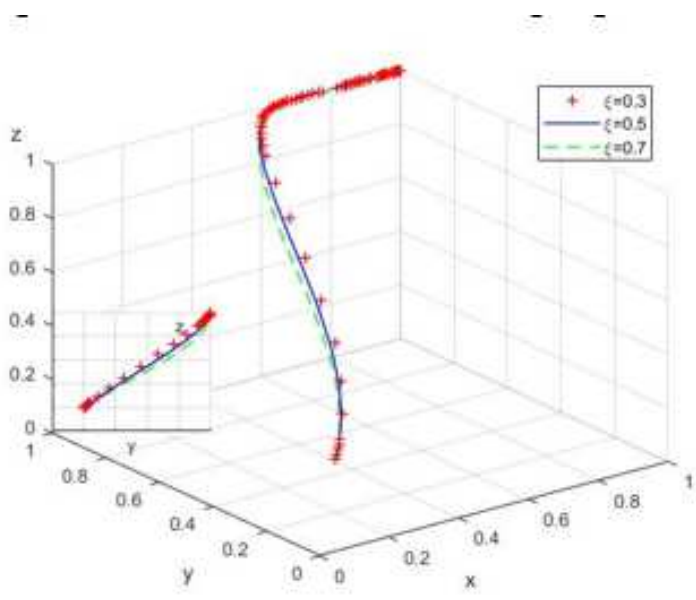

Fig. 15. The effect of $\xi$ on the strategy evolution 
intensity of subsidies and rewards must be within the scope allowed by the finances, otherwise it will increase the government's financial burden.

(3) The cost of promoting green distribution operations is negatively related to the willingness of member enterprise to implement green and low-carbon requirements. Hence the government needs to grant subsidies and rewards in a timely manner to stabilize member enterprises' profit expectations for implementing green and low-carbon requirements, and strengthen their confidence in green distribution operations.

(4) Based on the hypothesis of bounded rationality, member enterprises are likely to take advantage of information asymmetry to defraud government subsidies and rewards, or to conduct "free-riding" behavior on member enterprises with higher levels of green distribution operations. The above-mentioned speculative activities have a negative impact on the profit distribution and the stability of alliance. For this reason, an effective supervision mechanism and an information disclosure mechanism should be established by the government to restrain their speculative activities and require them to disclose the use of subsidies and rewards on time. In addition, the property rights of the joint distribution alliance, which is based on the private property rights of member enterprises, belongs to collective property rights, which has the shortcoming of unclear property right. Just as the "free-riding" behavior shows, it ostensibly means that member enterprise B can use the resources of member enterprise A for the green distribution operations at almost no cost, but it essentially exposes the absence of the property rights protection system in the alliance, resulting in member enterprise B obtaining profit that is not its own.Therefore, the alliance should establish and improve the property rights protection system to solve the profit distribution problems from the perspective of property rights protection. At the same time, it should also focus on the long-run, accelerating the implementation of the long-term mechanism of property rights protection, the assistance mechanism of property rights protection and the diversified resolution mechanism in the property rights disputes.

(5) The size of the additional benefit coefficient of member enterprise is positively related to the willingness of member enterprise to implement green and low-carbon requirements. Although the additional benefit coefficient has no significant relationship with whether the government adopts "incentives" strategy, the government needs to take the responsibility of reducing the institutional transaction costs, creating a good business environment for enterprises, protecting their legitimate rights under government regulations.

(6) The proportion of profit distribution has a direct impact on the member enterprise's participation in the greening process of distribution operations. Member enterprises with larger profit will be more active in promoting green distribution operations. The difference in the proportion of profit distribution depends on the differences in the member enterprises' resource endowments and corporate capabilities. The article doesn't find that the difference in the proportion of profit distribution is negatively related to the stability of alliance under government participation.

(7) The greater the weight of environmental benefit factor in the influencing factors of profit distribution, the more important the environmental benefit factor is, and the stronger the willingness of member enterprise to positively cooperate. The more profit caused by environmental benefit factor that the member enterprise A is allocated, the stronger its willingness to promote green distribution operations. Although member enterprise B's enthusiasm to promote green distribution operations will weaken, it does not change its willingness to positively cooperate, which indicates that the government is successful in creating internal incentives for the alliance. At this time, the government also needs to guide the formation of a benign competition and cooperation relationship within the alliance, encourage member enterprise A to help member enterprise B improve the green level of distribution operations under the premise of clear property rights, motivate both of them to share green distribution resources, increase environmental benefits, and eventually achieve "win-win".

Author Contributions: Conceptualization, Renbin Han and Mengke Yang; methodology, Renbin Han and Mengke Yang; software, Renbin Han; validation, Renbin Han; formal analysis, Renbin Han and Mengke Yang; investigation, Renbin Han; resources, Mengke Yang; data curation, Renbin Han; writing — original draft preparation, Renbin Han; writing — review and editing, Renbin Han; visualization, Renbin Han; supervision, M.Y.; project administration, Mengke Yang; funding acquisition, Mengke Yang. All authors have read and agreed to the published version of the manuscript.

Funding This research was funded by the Fundamental Research Funds for the Central Universities, BUPT, grant number "2018XKJC07" and the "Research on the innovation and development of urban logistics under the new situation", funded by the National Development and Reform Commission, China, grant number "JM-19-3-4".

\section{Declarations}

Ethics approval and consent to participate Not applicable.

Availability of data and materials Not applicable.

Consent for publication Not applicable.

Competing interests The authors declare that no competing interests.

\section{References}

Bi KX, Yang MK, Zhou XG, Latif Zahid, Zhu YF, Sun ZY (2020) Reducing carbon emissions from collaborative distribution: a case study of urban express in china. Environ. Sci. Pollut. Res 27(14): 16215-16230. 
Bin H, Zhang WK, Wang HF (2016) Research on profit distribution of urban joint distribution based on ecological factors. Seeker 2016(12): 99103 (in Chinese).

Chen XT, Li BY, Wang Z, Ma XP, Zhou Y (2019) Evolution game of logistics alliance with considering input elements and market power. Oper. Res. Manag. Sci 28(7): 64-71(in Chinese).

Du ZL, Lin BQ, Guan CX (2019) Development path of electric vehicles in China under environmental and energy security constraints. Resour.Conserv. Recy 143: 17-26.

Du ZP, Fu SS, Wang DD (2018) Evolutionary game of operational risk of cross - border logistics alliance based on system dynamics. Commer. Res 2018(4): 68-77 (in Chinese).

Du ZP, Gong XL (2018) Current situation of research on the operation mechanism of domestic and overseas cross-border logistics alliance. Chin. Bus. Mark 32(2): 37-49 (in Chinese).

Du ZP, Guo CL, Lu WH, Fu SS (2019) Cooperation analysis of cross-border e-commerce logistics alliance based on evolutionary game theory. Math. Pract. Theor 49(10): 22-32 (in Chinese).

Du ZP, Fu SS, Mu D, Wang DD (2020) Multi-party behavior game research of cross-border e-commerce logistics alliance based on 4PL. Chin. J. Manag. Sci 28(8): 104-113 (in Chinese).

Fan RG, Dong LL, Yang WG, Sun JQ (2017) Study on the optimal supervision strategy of government low-carbon subsidy and the corresponding efficiency and stability in the small-world network context. J Clean. Prod 168: 536-550.

Friedman D (1991) Evolutionary game in economics. Econometrica 59(3): 637-666.

Friedman D (1998) On economic applications of evolutionary game theory. J. Evol. Econ 8(1): 15-43.

Fu SS, Chen WD, Wang DD (2020) Research on stability of cross-border logistics alliance. Appl. Res. Comput 37(10): 2980-2983 (in Chinese).

Gu LQ, Xi LL, Wen SL (2017) Exploration on the low-carbon strategy based on the evolutionary game between the government and highway logistics enterprises. Agro Food Ind. Hi-Tech 28(1): 1796-1800.

Hafezalkotob A (2018) Modelling intervention policies of government in price-energy saving competition of green supply chains. Comput. Ind. Eng 119: 247-261.

Hafezalkotob A, Alavi A, Makui A (2016) Government financial intervention in green and regular supply chains: Multi-level game theory approach. Int. J. Manag. Sci. Eng 11(3): 167-177.

He HL, Li MK (2021) A tripartite game analysis on reverse logistics of express packaging under restricted control policies. Ind. Eng. Manag 26(1): 157-164 (in Chinese).

Hirte G, Tscharaktschiew S (2013) The optimal subsidy on electric vehicles in German metropolitan areas: A spatial general equilibrium analysis. Energ. Econ 40: 515-528.

Hu JL, Wen LX, Han SG (2018) Research on evolutionary game of urban cold chain logistics alliance from the perspective of information sharing. J. Zhejiang Sci-Tech Univ 40(3): 213-221 (in Chinese).

Huang ZF, Zhou YF, Yuan GL (2010) Investment analysis of logistics alliance' s specific asset on non- symmetric evolutionary game model. Heilongjiang Agric. Sci 2010(2): 104-108 (in Chinese).

Ji YQ, Shi GR (2018) Evolutionary game between logistics outsourcing enterprise, third-party logistics enterprise and the government. J. Commer. Econ 2018(9): 107-109 (in Chinese).

Li CB, Wang EJ, Yang Y (2017) An evolutionary game study on cold chain logistics resource allocation under government supervision. J. Beijing Jiaotong Univ 16(3): 108-118 (in Chinese).

Li LH, Hu ZD (2012) Evolution game model about symbiosis of asymmetric logistics alliance. J. Changsha Univ. Sci-Tech 9(1): 29-33 (in Chinese).

Li LX, Wang X, Lin Y, Zhou F, Chen S (2019) Cooperative game-based profit allocation for joint distribution alliance under online shopping environment. Asia Pac. J. Mark. Logist 31(2): 302-326.

Li SH, WANG XJ (2014) Obstacles to the development of green enterprise logistics and explore coping strategies from the perspective subjects of green enterprise logistics. Chin. J. Manag. Sci 22(11): 788-793 (in Chinese).

Liang W, Chen GQ, Wang X (2017) Research on reverse logistics in the development of e-commerce: game analysis on the different benefits of e-commerce enterprise and government and consumers. Ind. Econ. Rev 8(1): 67-79 (in Chinese).

Liu C, Huang WL, Yang C (2017) The evolutionary dynamics of China's electric vehicle industry - taxes vs. subsidies. Comput. Ind. Eng 113: 103-122.

Liu H, Li HM, Yang JQ (2015) Study on the relationship of logistics alliance based on evolutionary game theory. Logist. Eng. Manag 37(6): 3233 (in Chinese).

Long QQ, Tao XY, Shi Y, Zhang SZ (2021) Evolutionary game analysis among three green-sensitive parties in green supply chains. IEEE T. Evolut. Comput 25(3): 508-523.

Madani SR, Rasti-Barzoki M (2017) Sustainable supply chain management with pricing, greening and governmental tariffs determining strategies: A game-theoretic approach. Comput. Ind. Eng 105: 287-298.

Mahmoudi R; Rasti-Barzoki M (2018) Sustainable supply chains under government intervention with a real-world casecase study: An evolutionary game theoretic approach. Comput. Ind. Eng 116: 130-143.

Mu NY, Wang ZT, Hao JJ (2020) The co-evolutionary game of cross-border e-commerce and logistics. J. Transp. Eng. Inf 18(4):120-129 (in Chinee).

Peng BH, Wang YY, Elahi, E, Wei, G (2019) Behavioral game and simulation analysis of extended producer responsibility system's implementation under environmental regulations. Environ. Sci. Pollut. Res 26: 17644-17654.

Sheu JB, Chen YM (2012) Impact of government financial intervention on competition among green supply chains. Int. J. Prod. Econ 138 (1): 201-213.

Shi YY, Han BT, Zeng YC (2020) Simulating policy interventions in the interfirm diffusion of low-carbon technologies: An agent-based evolutionary game model. J Clean. Prod 250.

Sun T, Feng Q (2021) Evolutionary game of environmental investment under national environmental regulation in China. Environ. Sci. Pollut. Res 28 .

Sun XL, Wang DR, Zhang JG, Zhao RF (2014) Study on problems in urban cold chain logistics joint distribution based on cooperative evolution game analysis. Logist. Technol 33(23): 260-263+308 (in Chinese).

Wang HJ, Chen LH, Liu J (2021) An evolutionary game theory analysis linking manufacturing, logistics, and the government in low-carbon development. J. Oper. Res. Soc 25(1).

Wang WT, Zhang HQ (2015) Study on formation of logistics alliances based on dynamic game with incomplete information. Logist. Technol 34(9): 180-182 (in Chinese). 
Wu B, Liu PF, Xu XF (2017) An evolutionary analysis of low-carbon strategies based on the government-enterprise game in the complex network context. J Clean. Prod 141(1): 168-179.

Wu XF, Li J, Yang M (2014) Game analysis of regional logistics alliance's stability. Logist. Eng. Manag 36(2): 29-30 (in Chinese).

Xing XH, Hu ZH, Wang SW, Luo WP (2020) An evolutionary game model to study manufacturers and logistics enterprises' behavior strategies for information transparency in cold chains. Math. Probl. Eng. 2020.

Xu XY, Yang Y (2021) Tripartite evolutionary game of rail-road intermodal transport system under domination of government. J. Transp. Syst. Eng. Inf. Technol 21(2): 7-15 (in Chinese).

Xu Y, Shen JS, Wang CT (2011) Formation mechanism and cooperation games of logistics alliance. J. Transp. Syst. Eng. Inf. Technol. 11(2): 2126 (in Chinese).

Xu ZW, Peng ZX, Yang L, Chen X (2018) An improved shapley value method for a green supply chain income distribution mechanism. Int. J. Environ. Res. Public Health 15(9).

Yang MK, Han RB (2021) The profit allocation of joint distribution: traceability and system design. Logist. Res 2(1): 64-75 (in Chinese).

Yuan BY, He LF, Gu BM, Zhang Y (2018) The evolutionary game theoretic analysis for emission reduction and promotion in low-carbon supply chains. Appl. Sci-Basel 8(10).

Yu LJ, Yu J, Wang YM (2019) An analysis of evolutionary game simulation on collaborative innovation between manufacturing enterprises and logistics enterprises. Sci. Technol. Manag. Res 39(6): 1-10 (in Chinese).

Zhang HF, Wang S, Zhang ML (2017) Analysis on the influence of information resource sharing on the stability of logistics alliance. J. Commer. Econ 2017(19): 100-102 (in Chinese).

Zhang LP, Xue L, Zhou Y (2019) How do low-carbon policies promote green diffusion among alliance-based firms in China? An evolutionarygame model of complex networks. J Clean. Prod 210: 518-529 .

Zhang N, Zhang XX, Yang YJ (2019) The behavior mechanism of the urban joint distribution alliance under government supervision from the perspective of sustainable development. Sustainability 11(22).

Zhang RL, Hou ZK (2019) Equilibrium analysis of the behavioral strategies of e-commerce reverse logistics participators -- from the perspective of tripartite evolutionary game. J. Commer. Econ 2019(11): 108-110 (in Chinese).

Zhang SR, Yang MK, Zhou XG (2020) Mechanism of terminal express joint distribution based on evolutionary game. In Proceedings of the 2020 7th International Conference on Industrial Engineering and Applications (ICIEA), Bangkok, Thailand, 859-863 April 2020.

Zhang ZW, Xue YJ, Li JX, Gong LM, Wang L (2020) Supply chain logistics information collaboration strategy based on evolutionary game theory. IEEE Access 2020(8): 46102-46120.

Zhao R, Zhou X, Han JJ, Liu CL (2016) For the sustainable performance of the carbon reduction labeling policies under an evolutionary game simulation. Technol. Forecast. Soc 112: 262-274.

Zhou X, Zhao R, Cheng L, Min XF (2019) Impact of policy incentives on electric vehicles development: a system dynamics-based evolutionary game theoretical analysis. Clean. Technol. Envir 21(5): 1039-1053.

Zhu LY, Zhou L, Li HF (2021) Evolutionary game analysis of the role of government under sharing of logistics terminal distribution resources. Math. Pract. Theor 51(2): 54-67 (in Chinese).

Zou X, Zhang XN, Fu YZ, Peng CQ (2019) Analysis of logistics synergy stability of packaging enterprises from evolutionary game perspective. Math. Pract. Theor 49(15): 47-60 (in Chinese).

Zu YF, Chen LH, Fan Y (2018) Research on low-carbon strategies in supply chain with environmental regulations based on differential game. $J$ Clean. Prod 177: 527-546. 